\title{
Shear Behavior of Wheat-Concrete Interface during Monotonic and Cyclic Loading
}

\author{
Changnv Zeng ${ }^{1}$ and Yuke Wang $\mathbb{D D}^{2}$ \\ ${ }^{1}$ College of Civil Engineering and Architecture, Henan University of Technology, Zhengzhou 450001, China \\ ${ }^{2}$ College of Water Conservancy Engineering, Zhengzhou University, Zhengzhou 450001, China \\ Correspondence should be addressed to Yuke Wang; ykewang@163.com
}

Received 15 July 2019; Accepted 9 October 2019; Published 3 November 2019

Academic Editor: Yan-Ling Wei

Copyright (c) 2019 Changnv Zeng and Yuke Wang. This is an open access article distributed under the Creative Commons Attribution License, which permits unrestricted use, distribution, and reproduction in any medium, provided the original work is properly cited.

\begin{abstract}
The interface behavior between wheat and concrete plays a decisive role in the design of silo structures. In this paper, a series of strain-controlled monotonic direct shear (MDS) tests, cyclic direct shear (CDS) tests, and postcyclic direct shear (PCDS) tests were conducted to investigate the wheat-concrete interface behavior under monotonic and cyclic loading. The influence of cycle numbers, shear displacement amplitude, normal stress, and preloading consolidation was discussed in detail. In particular, the preloading consolidation simulates the partly discharging state of wheat. The values of peak stress increase with increasing displacement amplitude and cycles, and they change slightly after 10 cycles. The interface exhibits an overall contraction deformation during the MDS tests without preloading, but the contraction is suppressed by an alternating dilation during the DCS tests, and an overall small dilation occurs at small normal stress during PCDS tests. It is observed that the cyclic loading and preloading normal stresses result in an increasing peak strength, internal friction angle, and apparent cohesion, whereas a decrease in interface contraction deformation.
\end{abstract}

\section{Introduction}

The concrete silos called as special structures are traditionally used to store various materials, such as food grain, cement, and powder material $[1,2]$. The stored materials experience interactions with concrete silo walls. The wheatconcrete interaction mechanical properties play a key role in silo design [3-7]. In particular, a large portion of granular wheat in China is stored in concrete silos for three to five years, which is much longer than that in other developed countries $[8,9]$. Moreover, the stored wheat materials may be fully loaded into silos and partly unloaded several times, which results in preloading normal stress. Investigating the wheat-concrete interface shear behavior during storage time is of primary requirement in the design of silo structures.

Since the establishment of Janssen's theory in 1895, the static properties of wheat-wall interface were studied by many researchers [3, 4, 10-16]. Actually, granular wheat materials will experience storage, handling, or transportation process after their harvest, usually resulting in interface's shearing behavior. In addition, wheat materials may be subjected to dynamic loading resulting from earthquake or vibration, which include monotonic, cyclic, and postcyclic loadings. In contrast, the dynamic behavior of wheat-concrete interfaces under cyclic loading has not been so broadly considered. The properties developed for static loading are not directly suitable on predicting the behavior in dynamic loading conditions [17-20]. Therefore, it is necessary to acquire the interaction mechanism between concrete and granular wheat, which is greatly influenced by the loading conditions and stored materials $[21,22]$.

The conventional direct shear device can accommodate small particle specimens, such as sand, clay, silt, and so on. In recent years, some large-scale direct shear devices were used in geotechnical engineering for geotextile interface, sandstone materials, etc. [23-26]. The size of agriculture grain falls between sandstone and sand. The behavior of agricultural granular material has some difference from that 
of soil because of the grain shape, grain respiration action, and so on. Therefore, a dynamic direct shear device was developed suitable for agriculture grain to investigate the dynamic and monotonic shear properties of granular wheat.

In this paper, the shear stress and deformation behavior of wheat-concrete interface are presented from the monotonic and cyclic direct shear tests. Firstly, monotonic direct shear tests were conducted to discover the static shear behavior of wheat-concrete interface. Secondly, the influence of prepeak cyclic and postcyclic loading on the interface shear behavior is discussed using cyclic direct shear tests and postcyclic shear tests. The influence of shear displacement amplitude, cycle numbers, normal stress, and preloading stress is also examined in detail.

\section{Materials and Methods}

2.1. Materials. The wheat used is winter wheat grown in Henan Province, China. The dry basis moisture of wheat is $10.6 \%$, which is obtained by drying the wheat flour in an oven at temperatures of $105-110^{\circ} \mathrm{C}$ for at least 3 hours according to GB5497-85 [27].

The particle size of granular wheat is large enough to be inspected with naked eyes. The particle size distribution is conducted to quantify the specimen uniformity. In the case of granular wheat, the sieve analysis method is used to describe the particle size distribution. Two coefficients have been defined to provide guidance on distinguishing wheat based on the distribution of the particles. One of these is a numerical measure of uniformity, called the uniformity coefficient, $C_{\mathrm{u}}$, defined as equation (1). The other coefficient is the coefficient of curvature, $C_{c}$, defined as equation (2):

$$
\begin{aligned}
& C_{\mathrm{u}}=\frac{D_{60}}{D_{10}}, \\
& C_{\mathrm{c}}=\frac{\left(D_{30}\right)^{2}}{D_{60} \cdot D_{10}},
\end{aligned}
$$

where $D_{60}$ is the diameter of the wheat particles for which $60 \%$ of the particle are smaller and $D_{10}$ is the diameter of the wheat particles for which $10 \%$ of the particle are smaller. Both of these diameters are obtained from the grading curve shown in Figure 1. It is observed from Figure 1 that the effective particle size $D_{10}$, the uniformity coefficient $C_{\mathrm{u}}$, and coefficient of curvature $C_{\mathrm{c}}$ is $3.4 \mathrm{~mm}, 1.2$, and 1.0 , respectively, which indicates the wheat is a uniformly graded granular material.

The void ratio and the relative density of sample are calculated using the following equations, respectively:

$$
\begin{aligned}
e & =\frac{\rho_{\mathrm{s}}-\rho}{\rho}=\frac{\rho_{\mathrm{s}}}{\rho}-1, \\
D_{\mathrm{r}} & =\frac{e_{\max }-e}{e_{\max }-e_{\min }},
\end{aligned}
$$

where the value of $\rho_{\mathrm{s}}$ equals to the specific gravity of wheat $G_{\mathrm{s}}$ of $1.34, \rho$ is the density of wheat mass, and $e$ is the void ratio. The limit maximum and minimum void ratio of the granular

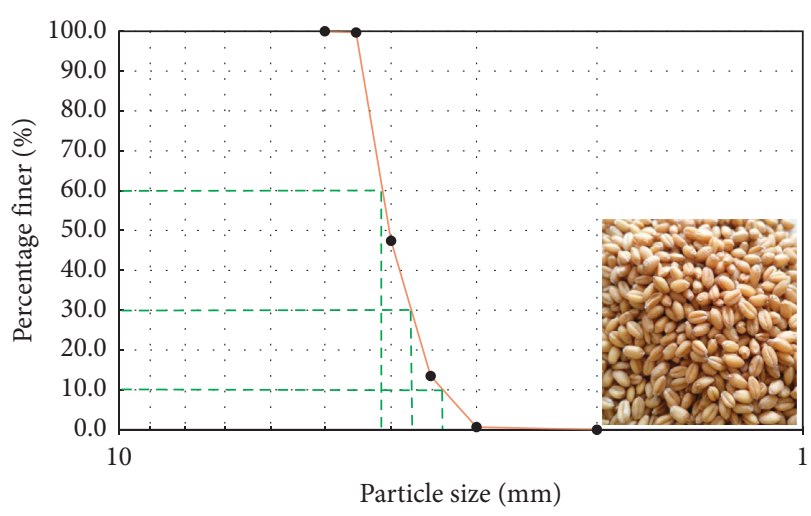

Figure 1: Particle size distribution curve.

wheat is 0.668 and 0.450 , referring to the test method of SL237-1999 [28].

In this study, the cylinder concrete block is used in the lower shear box with $100 \mathrm{~mm}$ in diameter and $50 \mathrm{~mm}$ in height. The concrete mixture is poured into the mold and cured for 14 days, which is considered as the impervious concrete material according to the concrete codes in China. The concrete block with density of $2200 \mathrm{~kg} / \mathrm{m}^{3}$ is mixed with fine sand, cement, and water.

2.2. Developed Direct Shear Test Apparatus. The test apparatus as shown in Figure 2 is newly developed based on common direct apparatus in geotechnical engineering. The direct shear apparatus consists of applied loading system, measurement system, shear box, and supported table. The shear box is divided by two half parts of upper box and lower box. The lower half shear box $(150 \mathrm{~mm} \times 150 \mathrm{~mm} \times 50 \mathrm{~mm})$ is driven by an electric motor to move horizontally, whereas the upper half is fixed in the same direction. The sample contact size is $100 \mathrm{~mm}$ in diameter.

The vertical stress is applied by a lever with weights independent of the horizontal shear stress. The device can provide horizontal cyclic shear as well as static shear with a displacement-controlled motor. The shear rate is controlled from 0.01 to $5 \mathrm{~mm} / \mathrm{min}$ by using an electric motor. The horizontal and vertical displacements are captured by the linear variable differential transformers, corresponding to the maximum capacity of $25 \mathrm{~mm}$ and $50 \mathrm{~mm}$ by a precision of $0.01 \mathrm{~mm}$. All loads and displacements measurements are acquired automatically by the measurement system.

2.3. Test Procedure. The test sample was prepared by pouring wheat into the upper box in 5 layers with the specified mass of wheat, while the concrete plate was put into the lower shear box. The specified mass of wheat in the upper was calculated using equation (1) at a void ratio of 0.532 , which is also calculated at the relative density of $55 \%$ using equation (2).

The monotonic, cyclic, and postcyclic behaviors of wheat-concrete interface were evaluated by a series of monotonic and cyclic direct shear tests. According to 


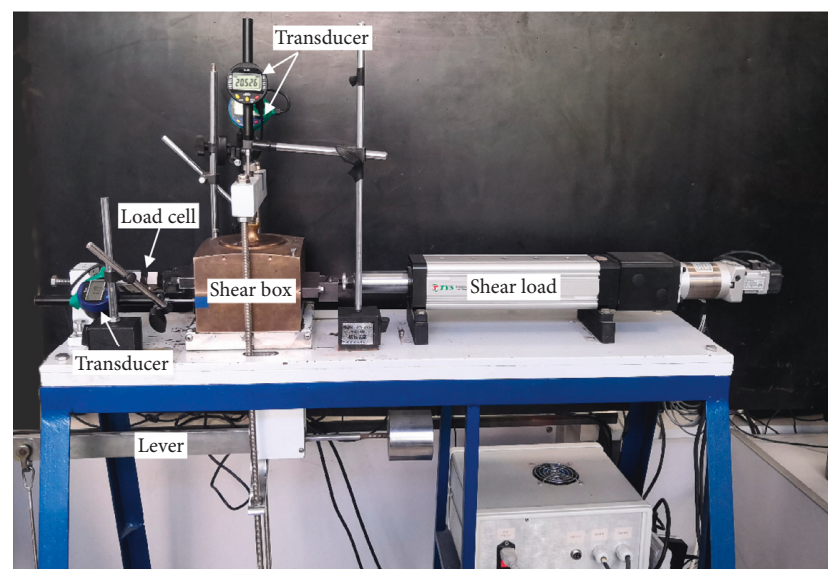

FIgURE 2: Direct shear box apparatus.

SL237-015, ASTM D5321, and preliminary experiment, the shearing rate was set as $2.4 \mathrm{~mm} / \mathrm{min}$ for reducing stress fluctuation during shearing [24].

In the monotonic direct shear (MDS) tests, the lower shear box was driven following path (1) from the position 0 shown in Figure 3. The tests were terminated at a horizontal shear displacement of $20 \mathrm{~mm}$. The applied normal stress is $50 \mathrm{kPa}, 100 \mathrm{kPa}$, and $150 \mathrm{kPa}$, respectively. The preloading consolidation of $200 \mathrm{kPa}$ was also considered, which simulated the process from full filled to partly unloaded during wheat storage stage. In this condition, the preloading of $200 \mathrm{kPa}$ was firstly applied; then, the normal stress is unloaded to the constant value of $50 \mathrm{kPa}, 100 \mathrm{kPa}$, and $150 \mathrm{kPa}$, respectively.

In the case of cyclic direct shear (CDS) tests, as seen in Figure 4, the loading shear path follows (1)-(2)-(3)-(4), which is defined as one cycle. During postcyclic direct shear (PCDS) tests, the loading path follows 0-(1) continuously after the last loading cycle of the CDS test stage. All the tests start from Point 0 as shown in Figure 3. Different influence factors, including cycle numbers, maximum shear displacement, normal stress, and preloading are considered in these tests. The details are listed in Table 1.

\section{Test Results}

3.1. Monotonic Behavior of Wheat-Concrete Interface. The development of horizontal shear stress and vertical displacement with horizontal shear displacement of wheatconcrete interface is shown in Figure 4 for MDS tests. In these tests, the imposed constant normal stresses are $50 \mathrm{kPa}$, $100 \mathrm{kPa}$, and $150 \mathrm{kPa}$, respectively. The wheat sample with a void ratio of 0.532 was poured into the upper shear box, while the concrete block is placed into the lower half. The tests with a preloading of $200 \mathrm{kPa}$ is considered compared with those applied by constant normal stress of $50 \mathrm{kPa}$, $100 \mathrm{kPa}$, and $150 \mathrm{kPa}$, respectively, which simulates partly unloaded condition during the storage.

The shear stresses of interfaces under various normal stresses in Figure 4(a) increase quickly to the peak value and then nearly maintain a constant strength with a little

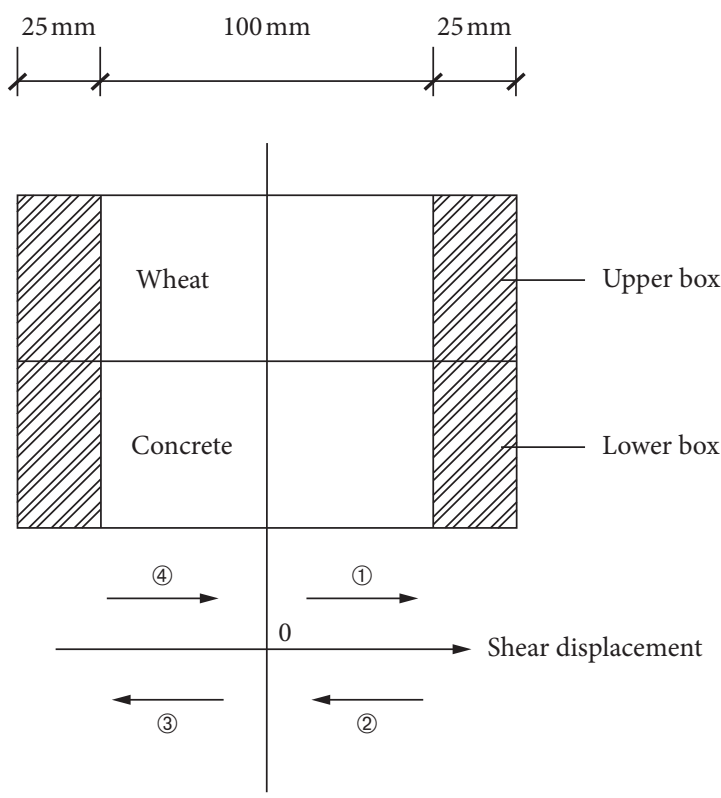

Figure 3: Cyclic shear paths.

fluctuation. It exhibits strain-softening behavior with different levels of strength decreasing after peak strength. The preloading of $200 \mathrm{kPa}$ enhances the interface strength at various normal stresses as shown in Figure 4(a). For example, under normal stresses of $50 \mathrm{kPa}, 100 \mathrm{kPa}$, and $150 \mathrm{kPa}$, the peak strength without preloading was 21.9, 38.6, and $54.5 \mathrm{kPa}$, respectively, while the peak strengths were $25.1,43.3$, and $57.8 \mathrm{kPa}$ with an applied preloading of $200 \mathrm{kPa}$.

Corresponding to the curve of vertical displacement against shear displacement, the contraction and dilation are denoted as negative and positive values, respectively. An overall contraction deformation is observed at a constant normal stress of 50 to $150 \mathrm{kPa}$ with dotted line as plotted in Figure 4(b). However, the preloading greatly reduces the contraction deformation with a solid line as plotted in Figure 4(b). Furthermore, even a small dilation deformation occurs at a normal stress of $50 \mathrm{kPa}$ with preloading.

Figure 5 presents the peak strengths for three normal stresses of $50 \mathrm{kPa}, 100 \mathrm{kPa}$, and $150 \mathrm{kPa}$ with or without preloading. The apparent adhesion $c=5.7 \mathrm{kPa}$ and a peak friction angle of $18.0^{\circ}$ were obtained for no preloading condition by using the Coulomb failure criterion. However, the peak strength was defined by apparent adhesion $c=9.3 \mathrm{kPa}$ and a peak friction angle of $18.1^{\circ}$ under the preloading condition. An obvious apparent adhesion occurred within the interface, which was also reported in other interfaces [24-26]. The preloading greatly enhances the apparent cohesion, while it has a slight increase in the interface peak friction angle. The strength behavior is similar to those of wheat materials and soil-structure interfaces; however, the interface dilatancy behavior shows some different behaviors [29-34]. For example, the wheat-concrete interface shows mostly contraction deformation both in monotonic and cyclic loading process without any preloading process. 


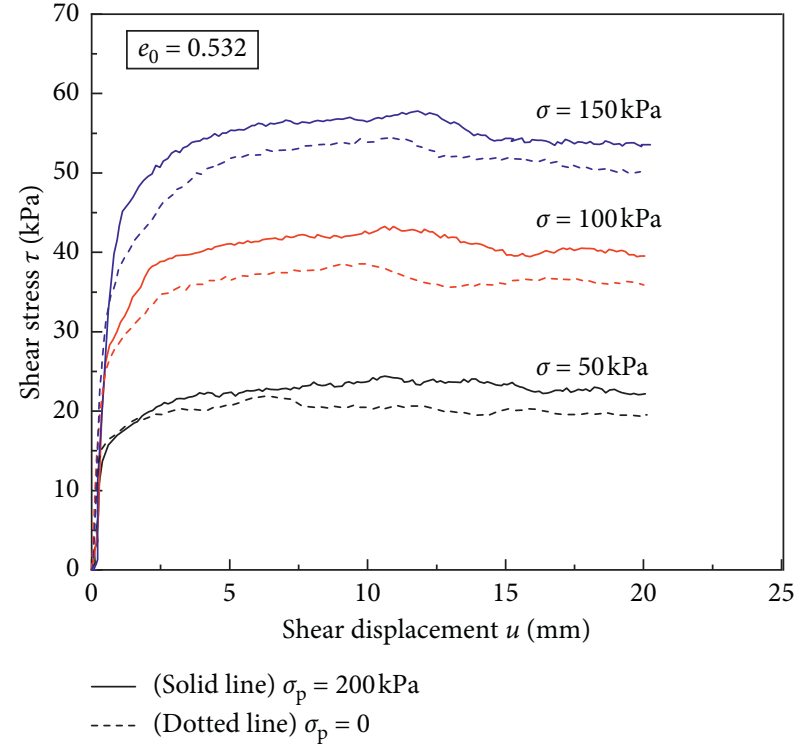

(a)

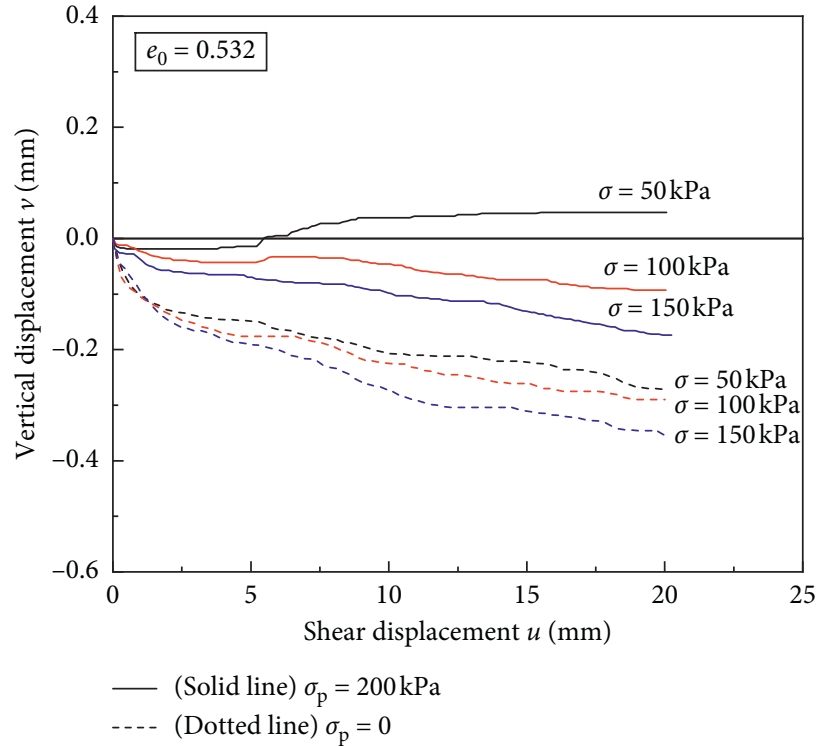

(b)

Figure 4: Monotonic direst shear tests of wheat-concrete interface: (a) shear stress-shear displacement; (b) vertical displacement-shear displacement.

TABLE 1: Test programs.

\begin{tabular}{lccccc}
\hline Test & Semiamplitude, $\Delta a(\mathrm{~mm})$ & Cycle number, $n_{c}$ & Normal stress, $\sigma(\mathrm{kPa})$ & Preloading, $\sigma_{\mathrm{p}}(\mathrm{kPa})$ & Postcyclic loading \\
\hline MDS1 & - & - & - & $50,100,150$ & 0 \\
MDS2 & - & 10 & $50,100,150$ & 200 & - \\
CDS1 & $2,3,4,6$ & $1,3,5,7,10$ & 100 & 0 & 0 \\
CDS2 & 3 & 10 & $50,100,150$ & 0 & Yes \\
CDS3 & 3 & 10 & $50,100,150$ & 200 & Yes \\
CDS4 & 3 & & & & Yes \\
\hline
\end{tabular}

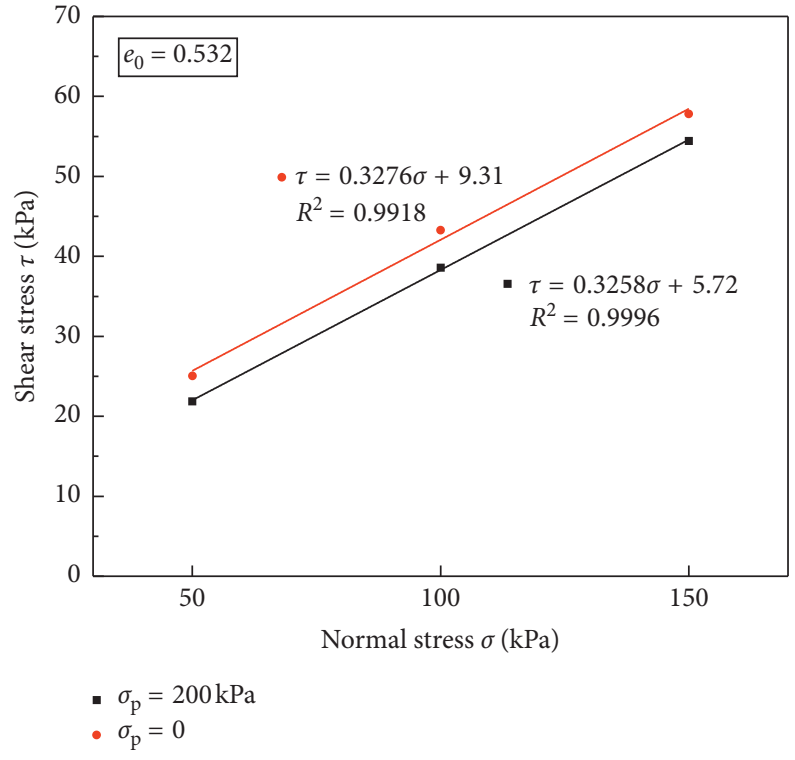

FIGURE 5: Effect of preloading on the strength parameters on MDS tests.

\subsection{Cyclic and Postcyclic Behavior of Wheat-Concrete Interface}

3.2.1. Dynamic Behavior of Interface from CDS Test Results. The cyclic shear behavior of interface is demonstrated in Figure 6. The loop curve of shear stress against shear displacement in the CDS test is plotted in Figure 6(a). The interface peak shear strength increases significantly during the first cycle. For all the other loading cycles, the shear stress increase is slight until a stable value reaches the $10^{\text {th }}$ cycle. During each one cycle shown in Figure 6(b), the value of positive peak strength (loading path from 0-(1)-(2)) is greater than that in the opposite direction (loading path from (2)-(3)-(4)), implying the different cyclic shear behaviors in shear directions of wheat-concrete interface. The peak strength is $50.2 \mathrm{kPa}$ in the first cycle (positive direction), and it reaches a stable value of $56.3 \mathrm{kPa}$ (positive direction) at the end of 10 cycles for normal stress of $150 \mathrm{kPa}$ with an initial void ratio of 0.532. It reveals the strength hardening with the cyclic loadings applied. The hysteretic loop area also expresses the strength hardening behavior, from which it increases with the increasing cycles and normal stresses (Table 2). 


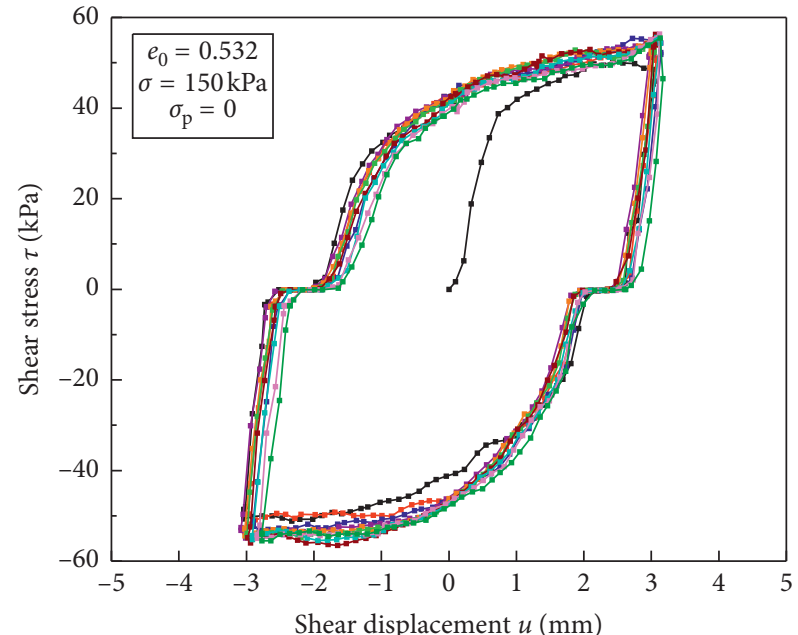

$$
\begin{array}{ll}
\rightarrow 1^{\text {st }} \text { cycle } & \rightarrow 5^{\text {th }} \text { cycle } \rightarrow 9^{\text {th }} \text { cycle } \\
\rightarrow 2^{\text {nd }} \text { cycle } & \rightarrow 6^{\text {th }} \text { cycle } \rightarrow 0^{\text {th }} \text { cycle } \\
\rightarrow 3^{\text {rd }} \text { cycle } & \rightarrow 7^{\text {th }} \text { cycle }
\end{array}
$$$$
\rightarrow 4^{\text {th }} \text { cycle } \quad \rightarrow \text { (a) } 8^{\text {th }} \text { cycle }
$$

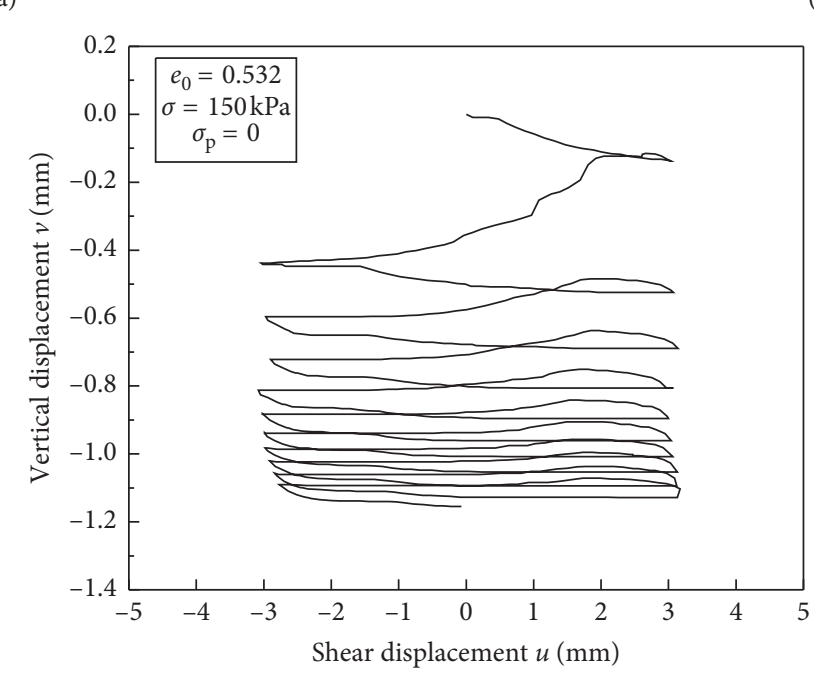

(c)

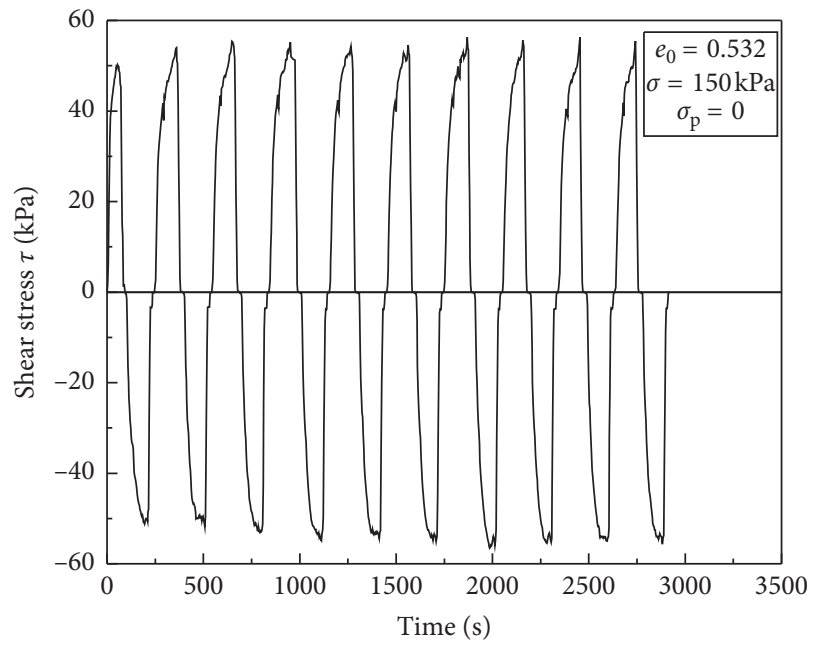

(b)

Figure 6: Typical dynamic test results: (a) shear stress versus shear displacement; (b) shear stress versus time; (c) vertical displacement

\begin{tabular}{|c|c|c|c|c|c|c|c|c|c|c|c|c|}
\hline \multirow{7}{*}{ Cycles } & \multicolumn{12}{|c|}{ Influences } \\
\hline & \multicolumn{3}{|c|}{ Normal stress, $\sigma(\mathrm{kPa})$} & \multicolumn{3}{|c|}{ Preloading, $\sigma_{\mathrm{p}}(\mathrm{kPa})$} & \multicolumn{3}{|c|}{$\Delta a(\mathrm{~mm})$} & \multicolumn{3}{|c|}{ Cycles number, $n_{c}$} \\
\hline & \multirow{2}{*}{\multicolumn{3}{|c|}{$\begin{array}{c}n_{c}=10 \\
\Delta a=3 \mathrm{~mm}\end{array}$}} & \multicolumn{3}{|c|}{$n_{c}=10$} & \multicolumn{3}{|c|}{$n_{c}=10$} & \multicolumn{3}{|c|}{$\Delta a=3 \mathrm{~mm}$} \\
\hline & & & & & $=3 \mathrm{n}$ & & & $\sigma_{\mathrm{p}}=\mathrm{c}$ & & & $\sigma_{\mathrm{p}}=\mathrm{c}$ & \\
\hline & & $\sigma_{\mathrm{p}}=0$ & & & 200 & & & 100 & & & 100 & \\
\hline & & $(\mathrm{kPa}$ & & & $(\mathrm{kP}$ & & & $a(\mathrm{~m}$ & & & $n_{c}$ & \\
\hline & 50 & 100 & 150 & 50 & 100 & 150 & 2 & 4 & 6 & 3 & 5 & 7 \\
\hline 2 & 170 & 256 & 361 & 139 & 254 & 339 & 134 & 416 & 719 & 264 & 251 & 262 \\
\hline 3 & 171 & 259 & 368 & 142 & 259 & 338 & 132 & 426 & 725 & 267 & 255 & 268 \\
\hline 4 & 169 & 262 & 368 & 145 & 259 & 336 & 130 & 420 & 727 & & 252 & 269 \\
\hline 5 & 173 & 264 & 369 & 145 & 261 & 332 & 132 & 421 & 725 & & 251 & 263 \\
\hline 6 & 176 & 263 & 370 & 142 & 259 & 330 & 129 & 419 & 737 & & & 263 \\
\hline 7 & 174 & 265 & 368 & 142 & 256 & 334 & 130 & 425 & 734 & & & 262 \\
\hline 8 & 175 & 264 & 364 & 142 & 253 & 335 & 131 & 421 & 729 & & & \\
\hline 9 & 177 & 267 & 358 & 141 & 262 & 336 & 131 & 422 & 736 & & & \\
\hline 10 & 175 & 265 & 358 & 142 & 259 & 338 & 128 & 422 & 740 & & & \\
\hline Average value & 173 & 263 & 365 & 142 & 258 & 335 & 131 & 421 & 730 & 265 & 252 & 265 \\
\hline
\end{tabular}
versus shear displacement.

TABLe 2: Hysteretic area of cyclic stress-strain curve. 


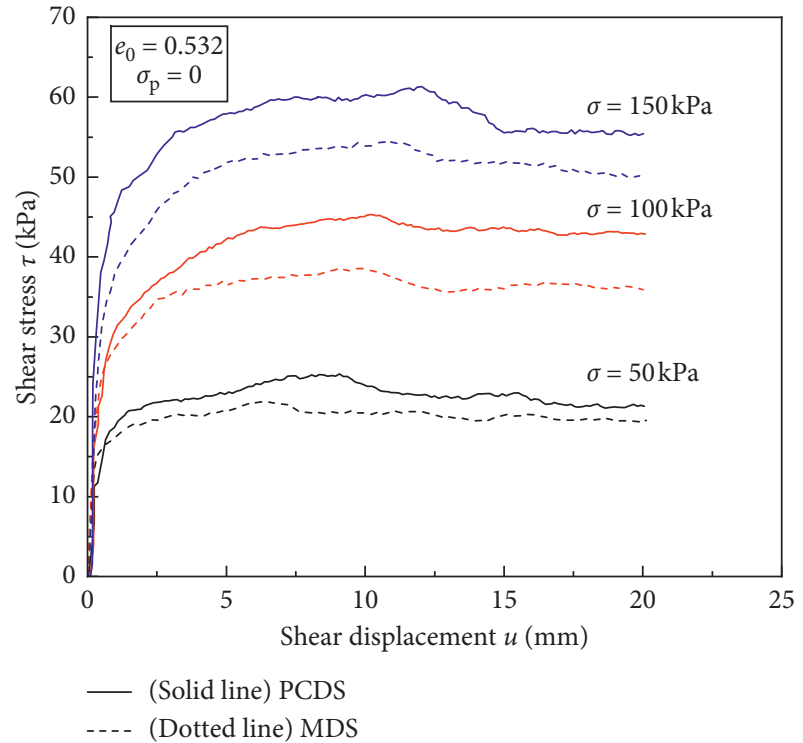

(a)

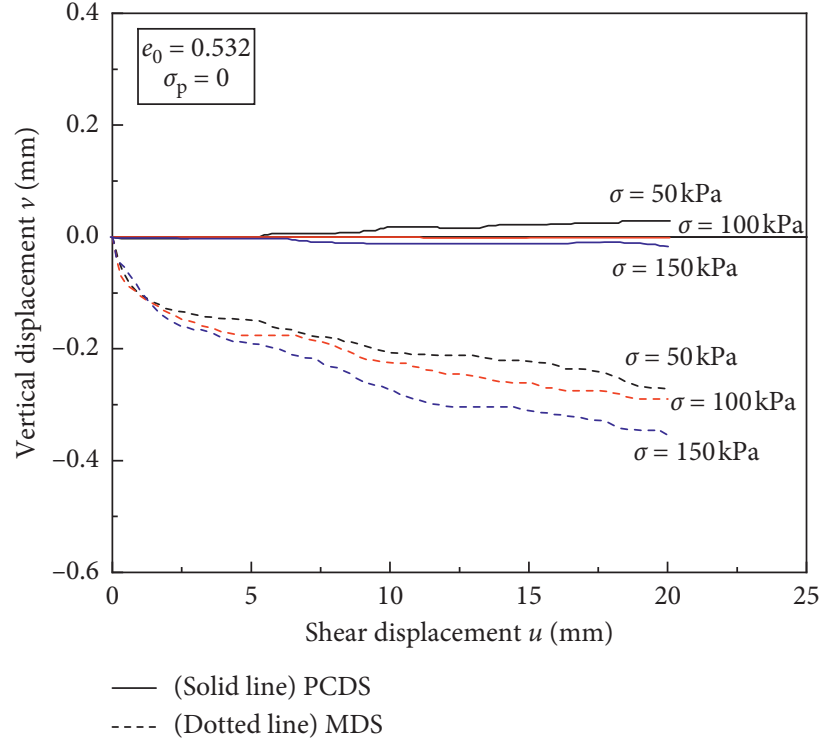

(b)

FIGURE 7: Results of MDS and PCDS: (a) shear stress versus shear displacement; (b) vertical displacement versus shear displacement.

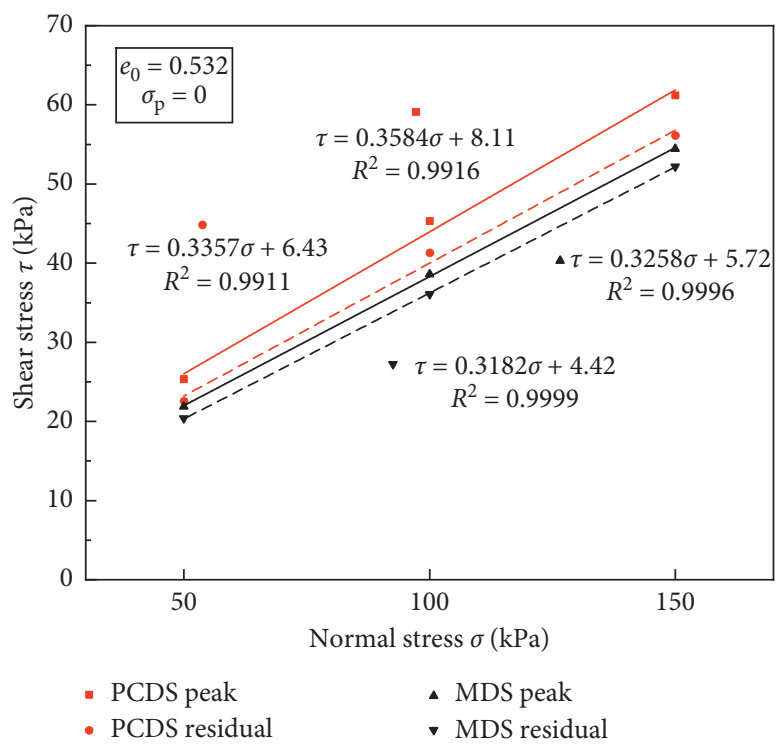

FIGURE 8: Effect of postcyclic and monotonic loading on peak shear stress versus normal stress.

With regards to the volumetric behavior, obvious contraction deformation appears in the CDS tests as shown in Figure 6(c). During each shear cycle, the vertical displacement experiences overall contraction (loading path from 0-(1) and some dilation in the initial stage later with a pronounced contraction (loading path from (1)-(4)). It can be discovered that the contraction contributes a leading deformation at each cycle and a whole contraction deformation performed during the applied cyclic loading. A gradual decreasing rate of contraction with the number of cycles can also be obtained in Figure 6(c). The cumulative vertical displacements in 10 cycles were $0.50,0.68,0.80$, $0.89,0.96,1.01,1.05,1.09,1.13$, and $1.16 \mathrm{~mm}$, respectively, implying a decreasing vertical displacement increment with cyclic numbers.

3.2.2. Interface Strength in PCDS Compared with MDS. The postcyclic monotonic loading was conducted after cyclic loading, which was also named as postcyclic direct shear (PCDS) stage. In this study, the peak shear strength at each cycle did not reach its peak value in the MDS tests. The shear stress versus shear displacement curves in the PCDS test were compared with those from the MDS test shown in Figure 7. It presents a distinct peak strength value for the two monotonic loading conditions at the same normal stress 

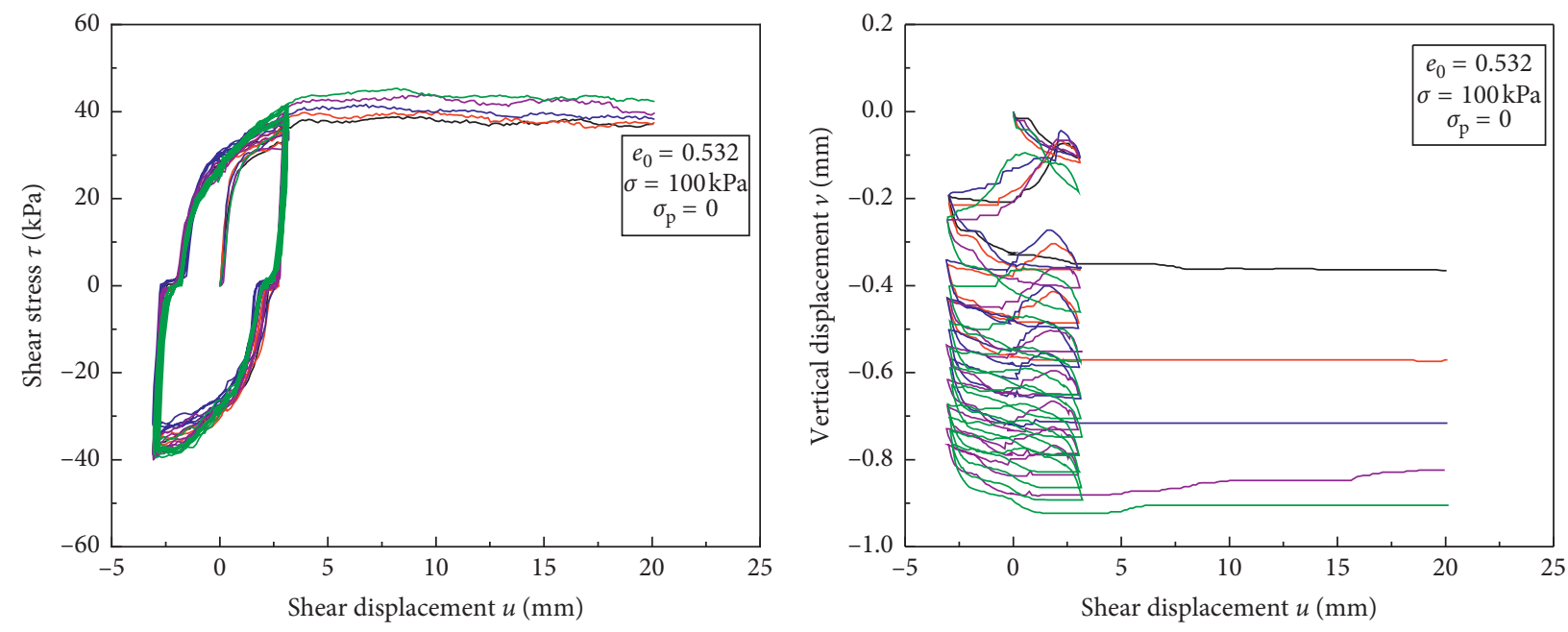

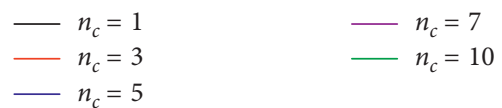

(a)

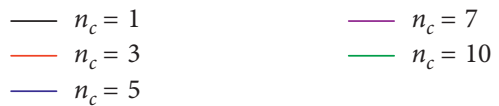

(b)

Figure 9: Effect of cycle number: (a) shear stress versus shear displacement; (b) vertical displacement versus shear displacement.

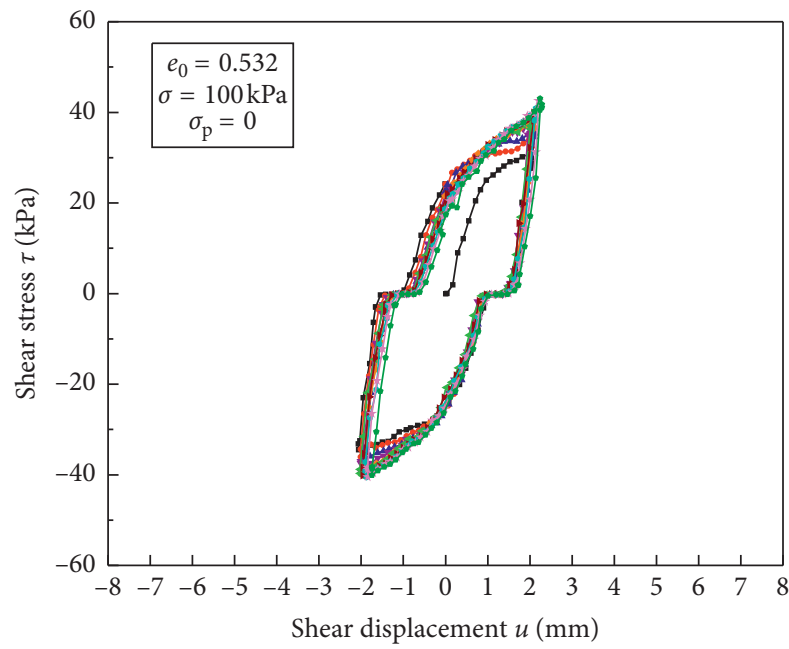

$$
\begin{array}{ll}
\rightarrow 1^{\text {st }} \text { cycle } & \rightarrow 5^{\text {th }} \text { cycle } \quad \rightarrow 9^{\text {th }} \text { cycle } \\
\rightarrow 2^{\text {nd }} \text { cycle } & -6^{\text {th }} \text { cycle } \quad \rightarrow 10^{\text {th }} \text { cycle } \\
\rightarrow 3^{\text {rd }} \text { cycle } & \rightarrow 7^{\text {th }} \text { cycle } \\
\rightarrow 4^{\text {th }} \text { cycle } & \rightarrow 8^{\text {th }} \text { cycle }
\end{array}
$$

(a)

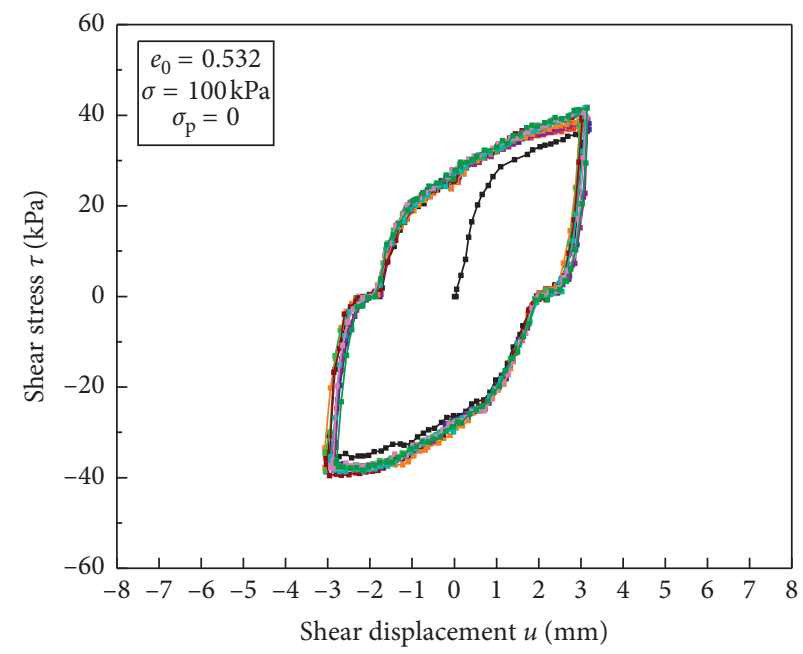

$$
\begin{array}{lll}
\rightarrow 1^{\text {st }} \text { cycle } & \rightarrow 5^{\text {th }} \text { cycle } \quad \rightarrow 9^{\text {th }} \text { cycle } \\
\rightarrow 2^{\text {nd }} \text { cycle } & \rightarrow 6^{\text {th }} \text { cycle } \quad \rightarrow 10^{\text {th }} \text { cycle } \\
\rightarrow 3^{\text {rd }} \text { cycle } & \rightarrow 7^{\text {th }} \text { cycle } \\
\rightarrow 4^{\text {th }} \text { cycle } & \rightarrow 8^{\text {th }} \text { cycle }
\end{array}
$$

(b)

Figure 10: Continued. 

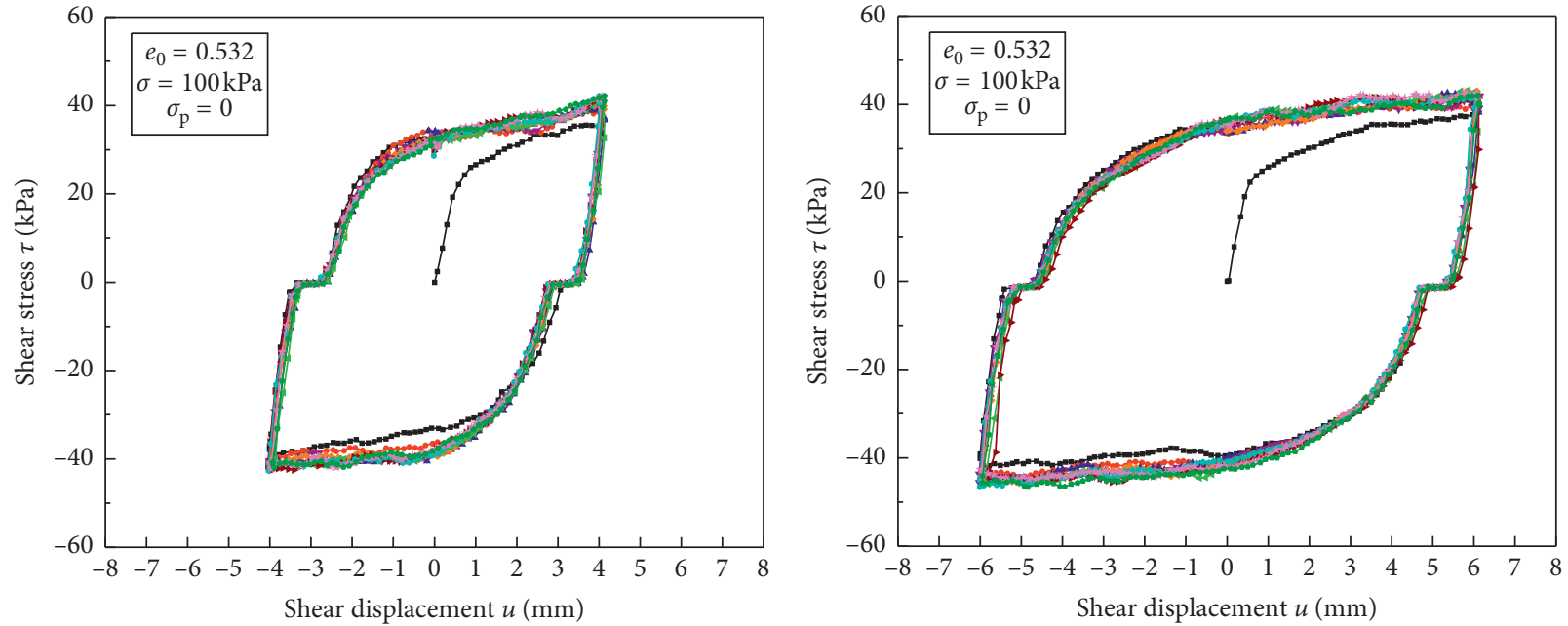

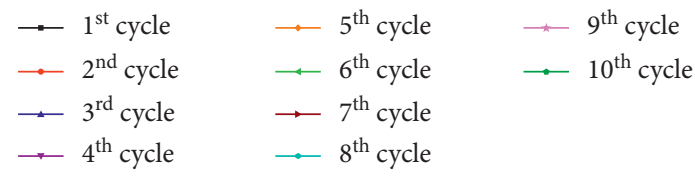

(c)

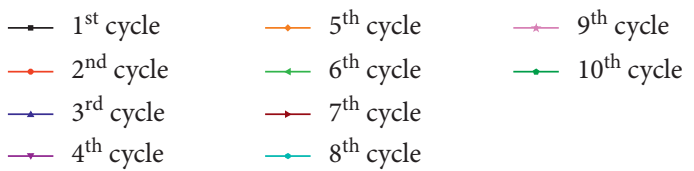

(d)

FIGURE 10: Effect of semiamplitude displacement on shear stress versus shear displacement: (a) $\Delta a=2 \mathrm{~mm}$; (b) $\Delta a=3 \mathrm{~mm}$; (c) $\Delta a=4 \mathrm{~mm}$; (d) $\Delta a=6 \mathrm{~mm}$.

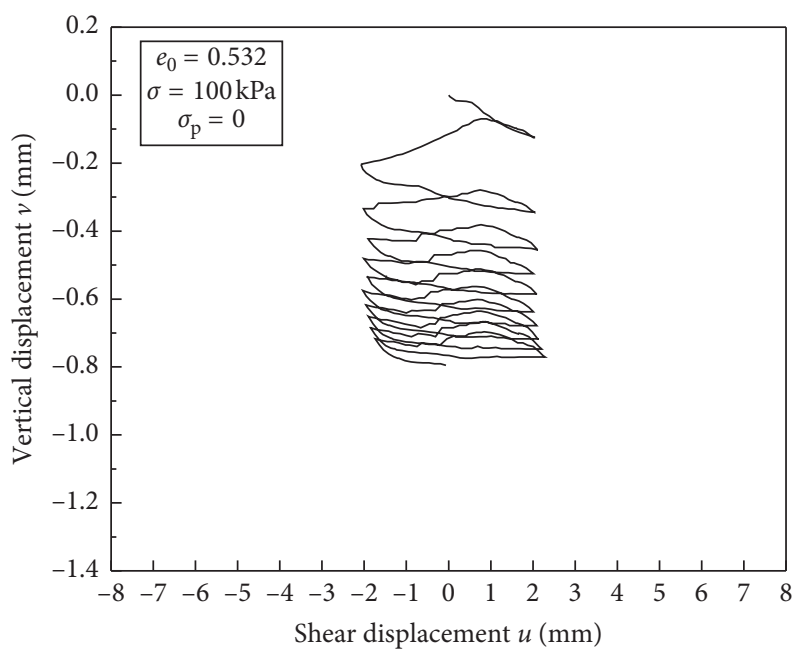

(a)

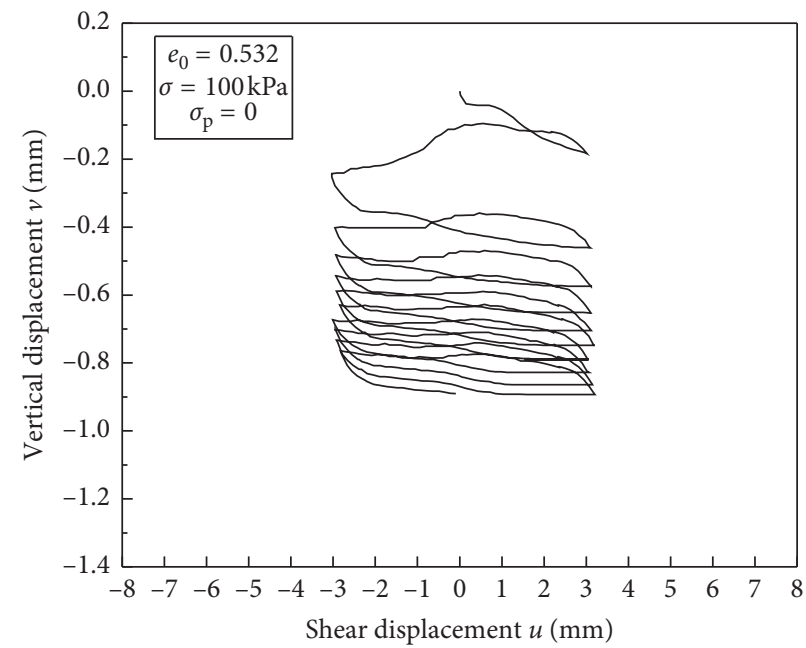

(b)

Figure 11: Continued. 


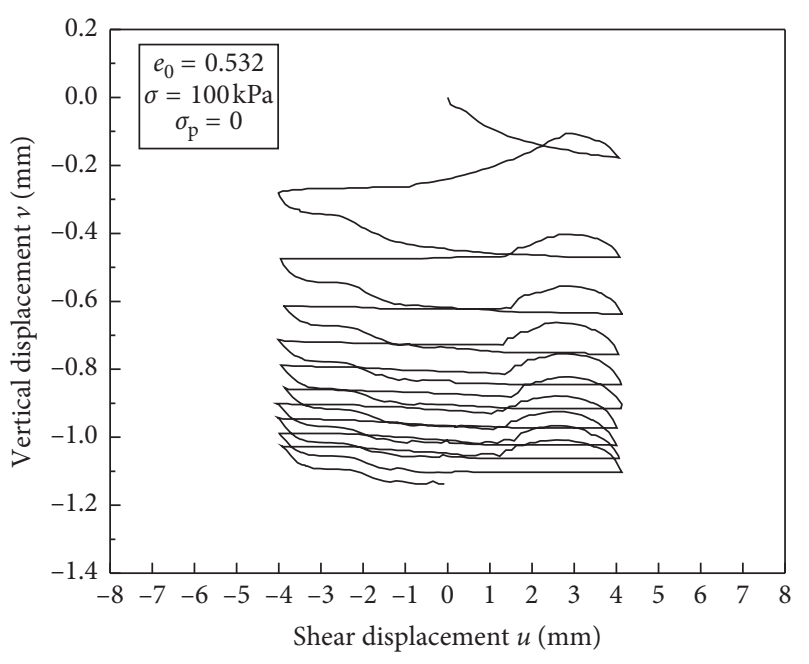

(c)

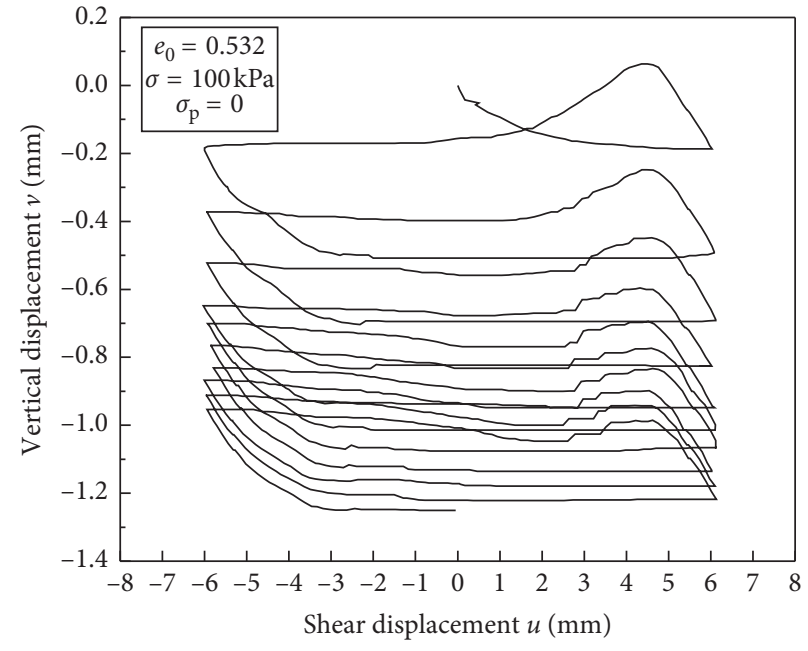

(d)

FigURE 11: Effect of semiamplitude displacement on shear stress versus shear displacement: (a) $\Delta a=2 \mathrm{~mm}$; (b) $\Delta a=3 \mathrm{~mm}$; (c) $\Delta a=4 \mathrm{~mm}$; (d) $\Delta a=6 \mathrm{~mm}$.

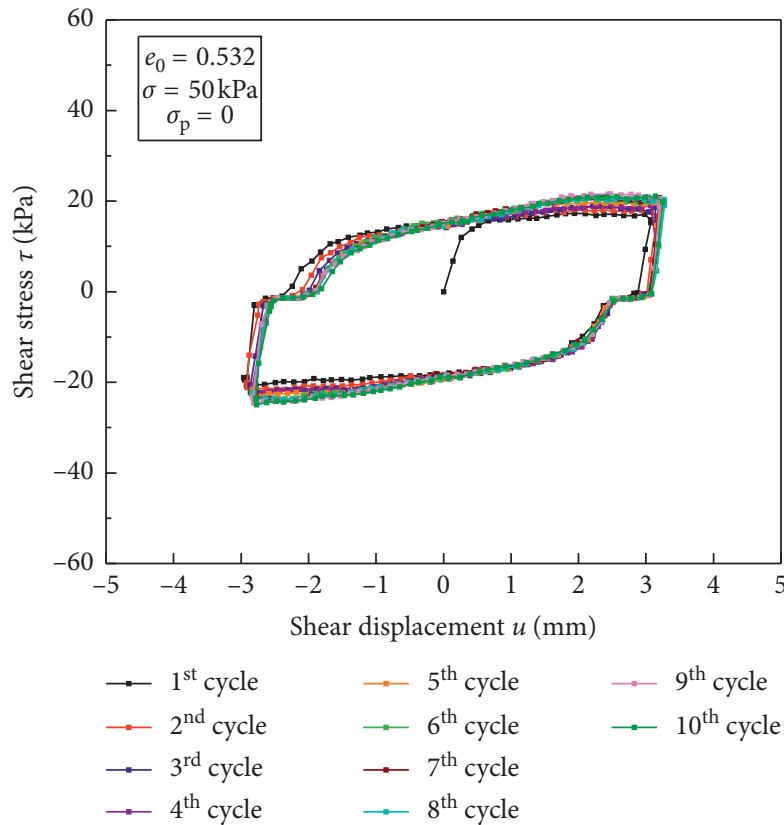

(a)

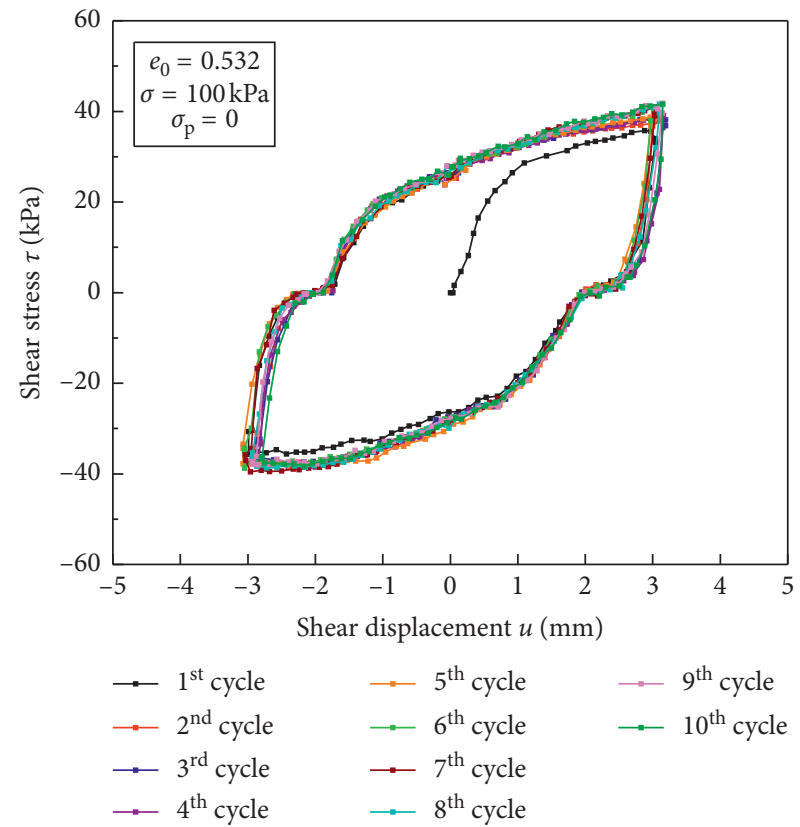

(b)

Figure 12: Continued. 


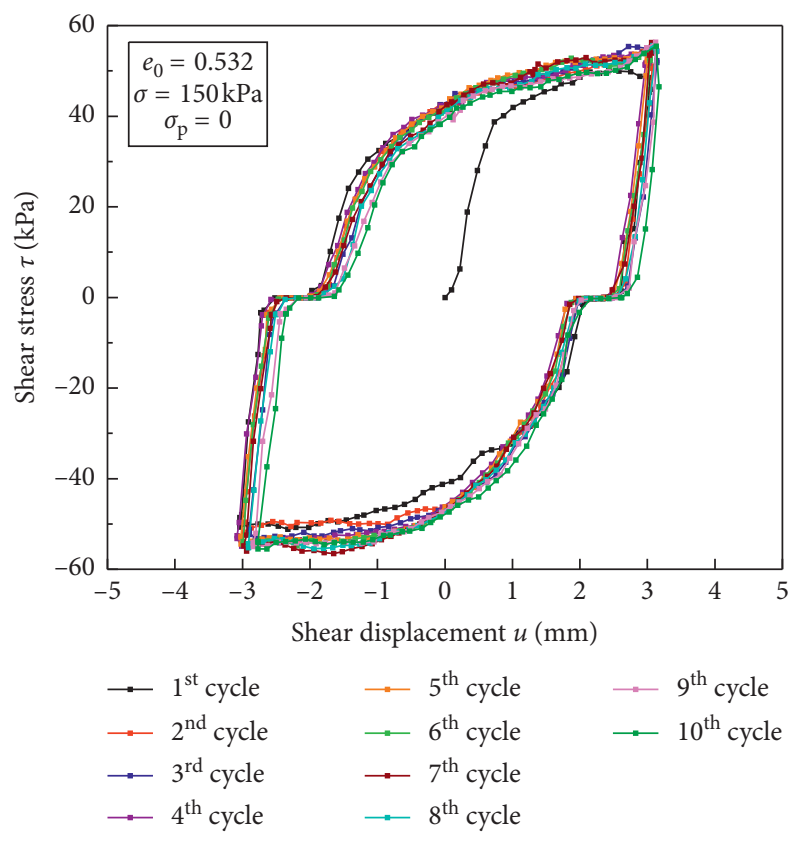

(c)

Figure 12: Effect of normal stress on shear stress: (a) $50 \mathrm{kPa}$; (b) $100 \mathrm{kPa}$; (c) $150 \mathrm{kPa}$.

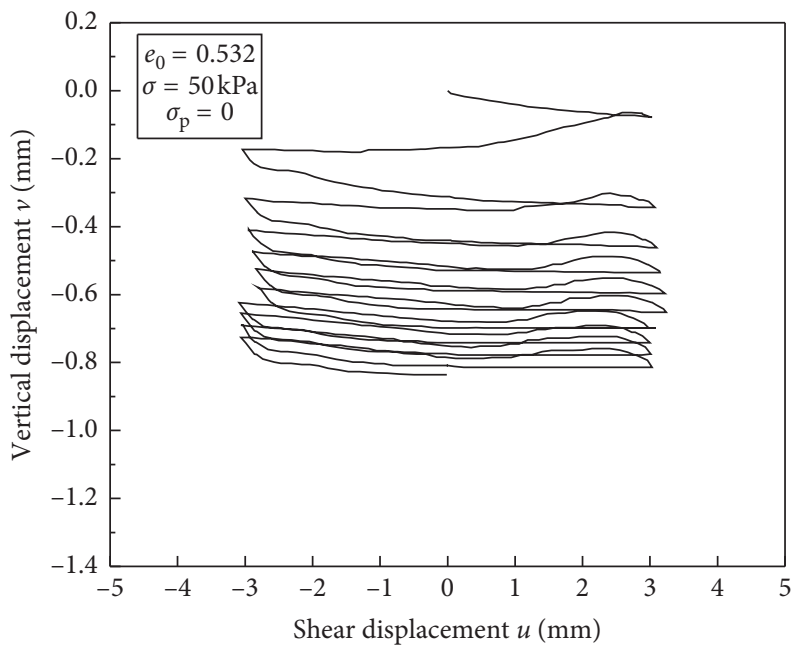

(a)

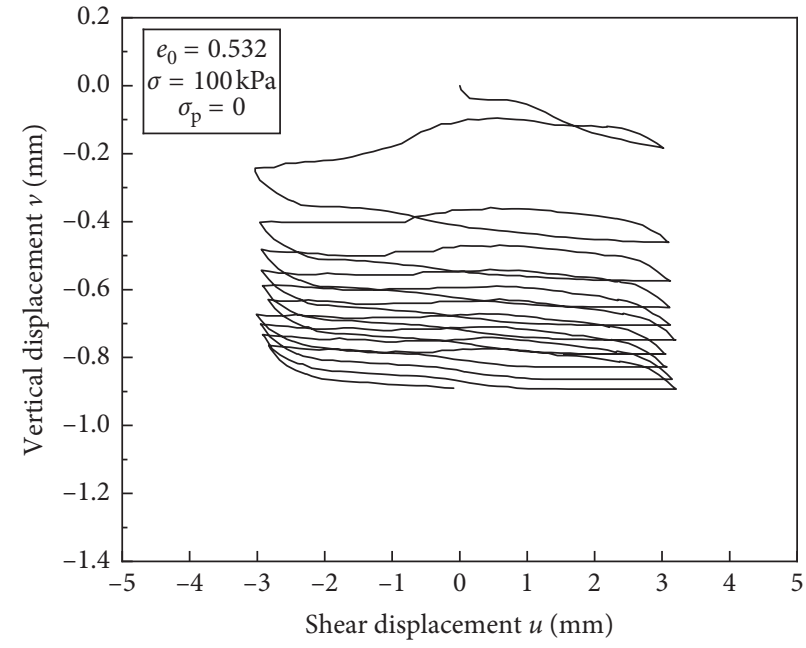

(b)

Figure 13: Continued. 


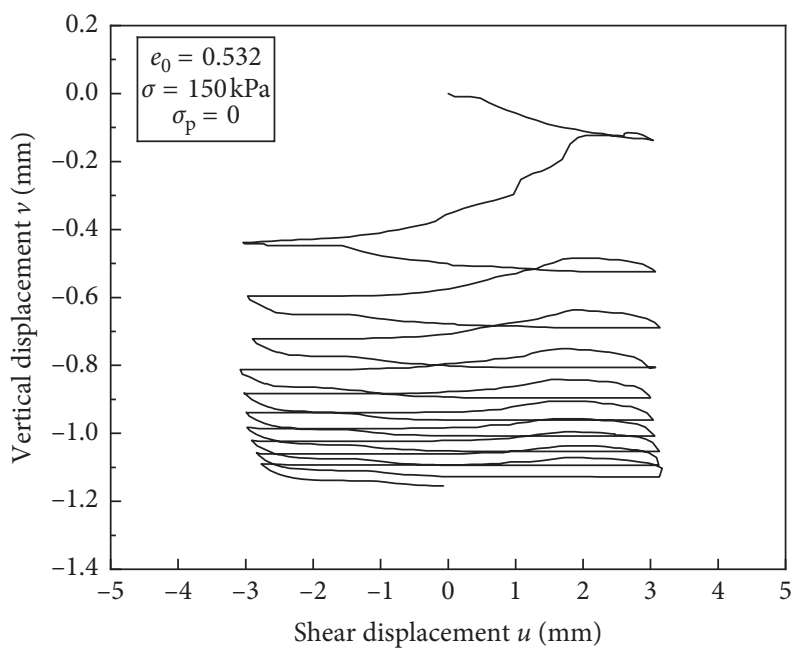

(c)

FIgURE 13: Effect of normal stress on vertical displacement: (a) $50 \mathrm{kPa}$; (b) $100 \mathrm{kPa}$; (c) $150 \mathrm{kPa}$.
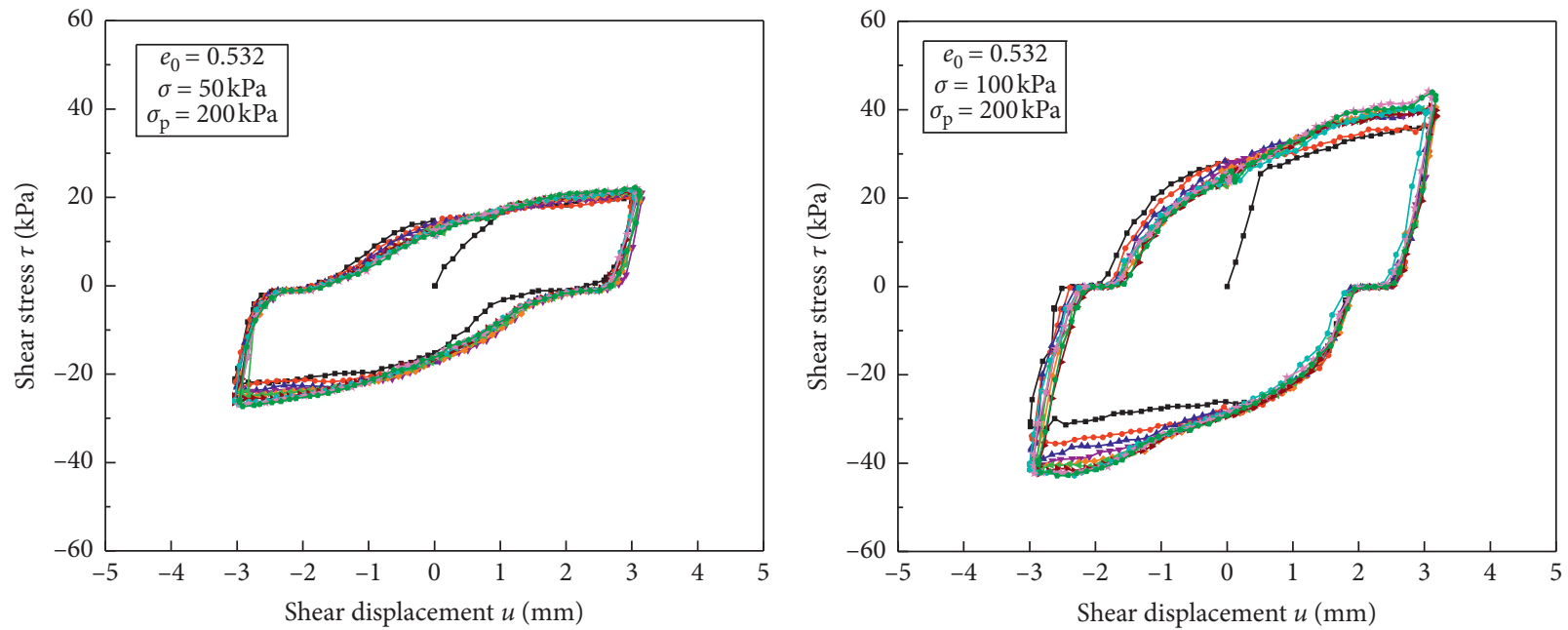

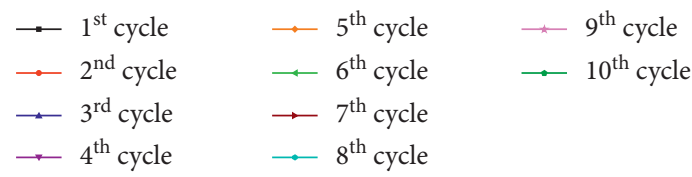

(a)

$\begin{array}{ll}\rightarrow 1^{\text {st }} \text { cycle } & \rightarrow 5^{\text {th }} \text { cycle } \quad * 9^{\text {th }} \text { cycle } \\ \rightarrow 2^{\text {nd }} \text { cycle } & \because 6^{\text {th }} \text { cycle } \quad \rightarrow 1^{\text {th }} \text { cycle } \\ \rightarrow 3^{\text {rd }} \text { cycle } & \rightarrow 7^{\text {th }} \text { cycle } \\ \rightarrow 4^{\text {th }} \text { cycle } & \rightarrow 8^{\text {th }} \text { cycle }\end{array}$

(b)

Figure 14: Continued. 


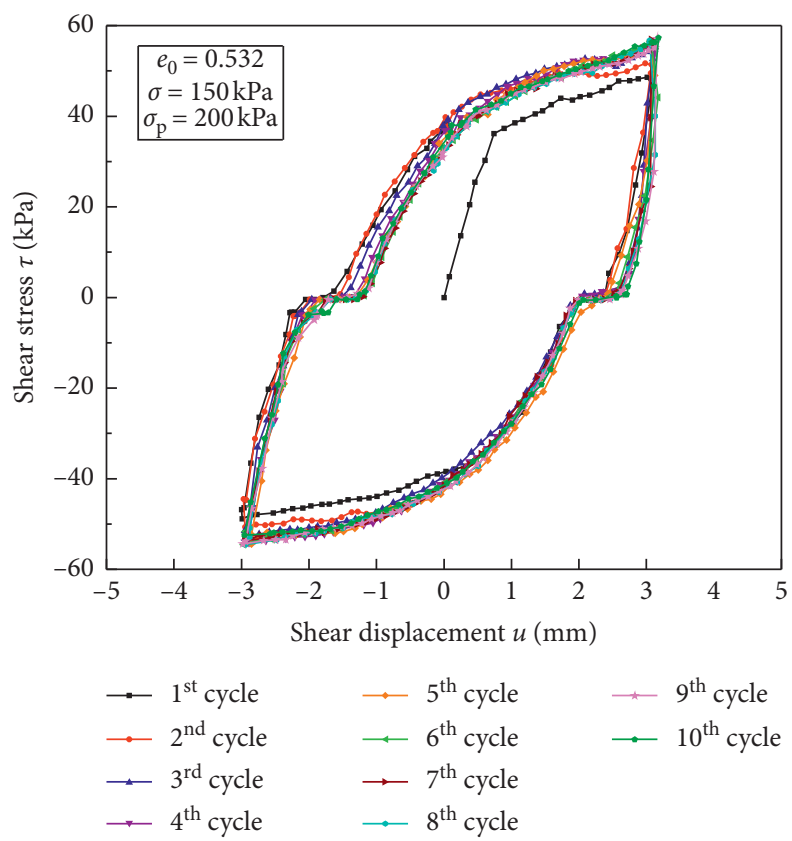

(c)

FIGURE 14: Effect of preloading of $200 \mathrm{kPa}$ on shear stress: (a) normal stress $=50 \mathrm{kPa}$; (b) normal stress $=100 \mathrm{kPa}$; (c) normal stress $=150 \mathrm{kPa}$.

with a void ratio of 0.532 . The peak strength was enhanced during the cyclic loading stage. The curve of shear stress against shear displacement exhibits different stress softening degrees at various normal stresses. The shear displacement for peak strength during the PCDS stage was larger than that in the MDS test. The peak strengths at normal stresses of $50 \mathrm{kPa}, 100 \mathrm{kPa}$, and $150 \mathrm{kPa}$ are $21.9 \mathrm{kPa}, 38.6 \mathrm{kPa}$, and $54.5 \mathrm{kPa}$ in MDS tests, with the corresponding shear displacements of $6.7 \mathrm{~mm}, 9.9 \mathrm{~mm}$, and $10.9 \mathrm{~mm}$, respectively. For PCDS tests, the peak strengths at normal stresses of $50 \mathrm{kPa}, 100 \mathrm{kPa}$, and $150 \mathrm{kPa}$ are $25.4 \mathrm{kPa}, 45.3 \mathrm{kPa}$, and $61.2 \mathrm{kPa}$, respectively, which are corresponding to shear displacements of $9.1 \mathrm{~mm}, 10.2 \mathrm{~mm}$, and $11.9 \mathrm{~mm}$, respectively. The apparent adhesion $c=5.7 \mathrm{kPa}$ and a peak friction angle of $18.0^{\circ}$ were obtained for the MDS test based on the coulomb failure criterion as shown in Figure 8. The peak strength was defined by apparent adhesion $c=8.1 \mathrm{kPa}$ and a peak friction angle of $19.7^{\circ}$ for the PCDS test. The cyclic loading has a slight effect on the apparent cohesion. The similar results are observed for the residual of MDS and PCDS tests as shown in Figure 8.

The vertical displacements in PCDS tests differ greatly from those in MDS tests as shown in Figure 7(b). It can be seen that vertical displacement exhibited far less contraction in PCDS than that in MDS tests. Even some dilative behaviors were seen in the PCDS test, whereas the overall contraction occurred during the MDS test.

\section{Discussion}

4.1. Influence of Cycle Numbers. The influence of cycle numbers $1,3,5,7$, and 10 was plotted in the curve of shear stress versus shear displacement of the interface shown in
Figure 9. The void ratio of sample is 0.532 at a normal stress of $100 \mathrm{kPa}$ without preloading. The peak strength values in PCDS were $38.8 \mathrm{kPa}, 40.0 \mathrm{kPa}, 41.7 \mathrm{kPa}, 43.3 \mathrm{kPa}$, and $45.3 \mathrm{kPa}$, respectively, for cycle numbers $1,3,5,7$, and 10 . It is found from Figure 9(a) that the mobilized shear stress increased with the increasing cycle number during the PCDS stage. Furthermore, the densification caused by cyclic loading affects the final peak strength significantly during the cyclic loading stage, which tends to be a denser sample for the following postcyclic monotonic loading stage. It is shown in Table 2 that the hysteretic area has slight influence with different cycles during cyclic loading.

The increment of vertical displacement at different cycle numbers exhibits a similar contraction deformation path at each cycle as shown in Figure 9(b). The value of the final vertical contraction deformation increased with increasing cycle numbers, while the generation rate decreased with the increasing cycle number.

4.2. Influence of Semiamplitude Shear Displacement $\Delta a$. The experiment results in Figure 10 show the influence of different semiamplitude shear displacement $\Delta a$ on cyclic and postcyclic strengths. It is found that the peak strength is affected by $\Delta a$ in the initial cycles. However, the peak strength trends to be constant in the $10^{\text {th }}$ cycle for different levels with different values of $\Delta a$. As shown in Table 2, the hysteretic area greatly increased with the increasing of $\Delta a$, which shows that the magnitude of cyclic loading has a significant influence on the energy dissipation.

The values of interface peak shear strength in PCDS with $\Delta a$ equals to $2 \mathrm{~mm}, 3 \mathrm{~mm}, 4 \mathrm{~mm}$, and $6 \mathrm{~mm}$ were $45.1 \mathrm{kPa}$, $45.3 \mathrm{kPa}, 46.0 \mathrm{kPa}$, and $44.8 \mathrm{kPa}$, respectively. It implies that 


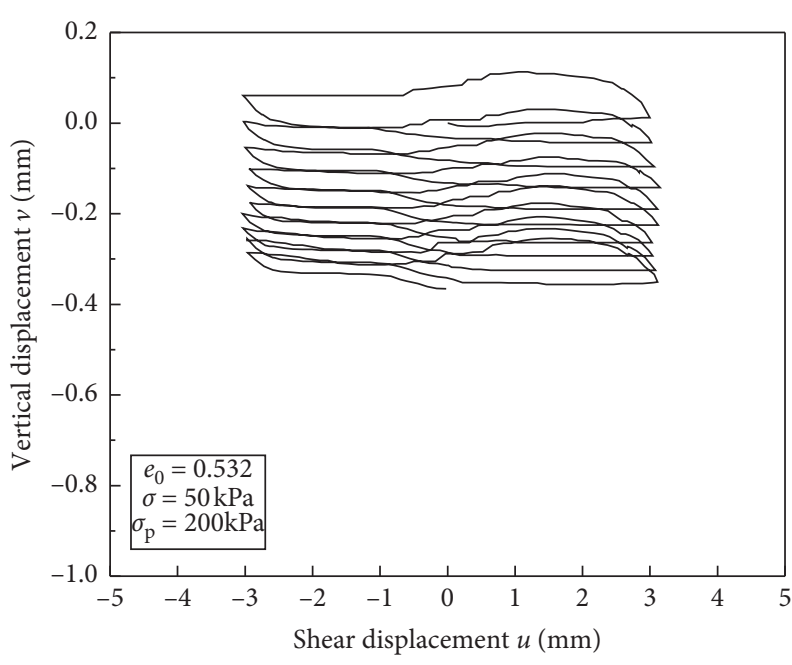

(a)

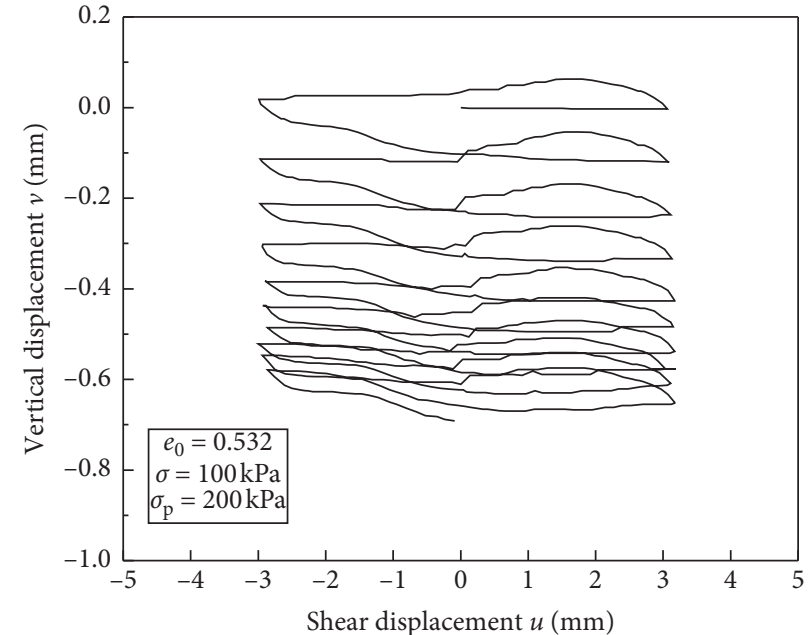

(b)

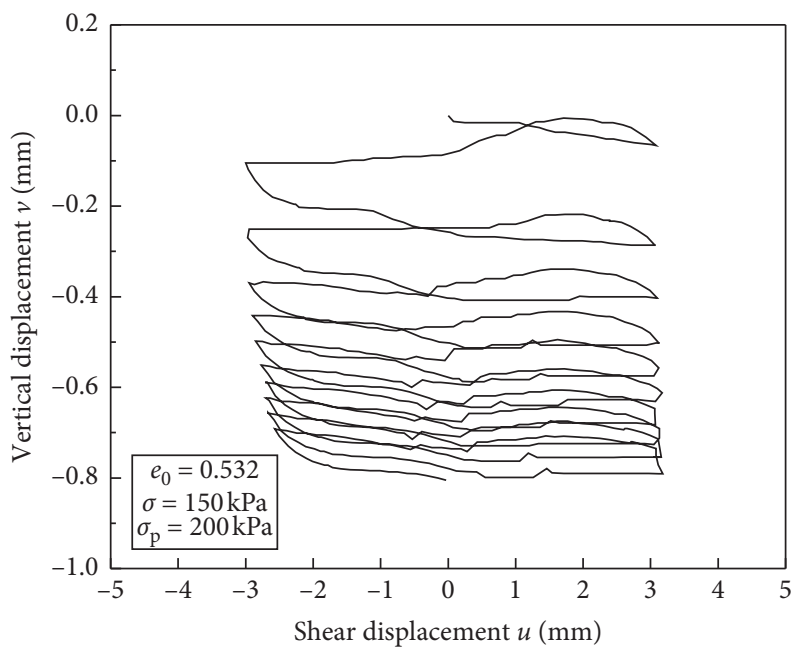

(c)

Figure 15: Effect of preloading of $200 \mathrm{kPa}$ on vertical displacement: (a) normal stress $=50 \mathrm{kPa}$; (b) normal stress $=100 \mathrm{kPa}$; (c) normal stress $=150 \mathrm{kPa}$.

TABle 3: Preloading effects on the strength parameters.

\begin{tabular}{lcccc}
\hline \multirow{2}{*}{ Tests } & \multicolumn{2}{c}{ Peak state } & \multicolumn{2}{c}{ Residual state } \\
& Cohesion $(\mathrm{kPa})$ & Friction angle $\left(^{\circ}\right)$ & Cohesion $(\mathrm{kPa})$ & 4.4 \\
MDS1 $\left(\sigma_{\mathrm{p}}=0\right)$ & 5.7 & 18.0 & 7.1 & 17.7 \\
MDS2 $\left(\sigma_{\mathrm{p}}=200 \mathrm{kPa}\right)$ & 9.3 & 18.1 & 6.4 & 17.5 \\
PCDS3 $\left(\sigma_{\mathrm{p}}=0\right)$ & 8.1 & 19.7 & 7.6 & 18.6 \\
PCDS4 $\left(\sigma_{\mathrm{p}}=200 \mathrm{kPa}\right)$ & 10.7 & 19.4 & 18.1 \\
\hline
\end{tabular}

the interface-mobilized peak strength during PCDS monotonic loading is slightly affected by $\Delta a$. The effect of $\Delta a$ decreases with increasing loading cycles. For $\Delta a$ of $6 \mathrm{~mm}$, the peak strength exceeds the peak strength in MDS, which indicates the sample failed before cyclic loading resulting in the degradation of peak strength in PCDS test. In this paper, the $\Delta a$ value of $3 \mathrm{~mm}$ is set for other tests.

Figure 11 plots the curve of vertical displacement versus shear displacement with different $\Delta a$ values. For each $\Delta a$, the interface experiences an alternating phase of initial dilation and large contraction during each cyclic cycle. It is also shown that the large contraction suppressed the initial dilation. The maximum contraction deformation during cyclic loading stage increased with the increase of $\Delta a$ from $2 \mathrm{~mm}$ to $6 \mathrm{~mm}$, which were $0.80 \mathrm{~mm}, 0.89 \mathrm{~mm}, 1.14 \mathrm{~mm}$, and $1.25 \mathrm{~mm}$, respectively.

4.3. Influence of Normal Stress. The results in Figure 12 show the effect of normal stress on interface behavior in cyclic 
direct shear tests, which is $50 \mathrm{kPa}, 100 \mathrm{kPa}$, and $150 \mathrm{kPa}$, respectively. The tests were undertaken at a shear displacement $\Delta a$ of $3 \mathrm{~mm}$ and 10 cyclic numbers. It can be seen that the increasing normal stress causes an increasing ultimate peak shear stress. For normal stresses of $50 \mathrm{kPa}$, $100 \mathrm{kPa}$, and $150 \mathrm{kPa}$ with a void ratio of 0.532 , the ultimate shear stresses in the $10^{\text {th }}$ cycle were $21.5 \mathrm{kPa}, 41.8 \mathrm{kPa}$, and $56.3 \mathrm{kPa}$, respectively. With the increasing of normal stress, the hysteretic area greatly increases, which shows an increasing resistance of cyclic loading.

Figure 13 shows that interface displayed larger contraction subjected to larger normal stresses during the cyclic loading stage. For normal stresses of $50 \mathrm{kPa}, 100 \mathrm{kPa}$, and $150 \mathrm{kPa}$, the maximum contraction during cyclic loading was $0.84 \mathrm{~mm}, 0.89 \mathrm{~mm}$, and $1.16 \mathrm{~mm}$, respectively, which were attributed to confinement of the interface.

4.4. Influence of Preloading. During the storage conditions, the normal stress changed with the loading or partly unloading of wheat from silos. Thus, the effect of preloading is necessarily examined. The preloading is selected as $200 \mathrm{kPa}$ and then unloaded to $150 \mathrm{kPa}, 100 \mathrm{kPa}$, and $50 \mathrm{kPa}$. It can be obtained in Figures 14 and 15 that the cyclic peak strength and postcyclic peak strength are enhanced by the preloading greatly, whereas the contraction deformation decreases due to the densification of preloading. The interface strength parameters including apparent cohesion and friction angle at peak strength and residual strength during the PCDS and MDS stages are listed in Table 3, which describes the effect of preloading on the strength parameters. It can be obtained that the apparent cohesion is enhanced by the preloading, whereas it had little effect on the friction angle.

\section{Conclusions}

The cyclic and postcyclic shear behaviors of wheat-concrete were evaluated by comparing with the monotonic shear behaviors. The effect of shear displacement amplitude, cycle numbers, normal stress, and preloading during storage periods were discussed in detail. The conclusions are as follows:

(1) The peak shear strength in PCDS tests is greater than those in MDS tests and CDS tests. The cyclic loading also enhanced the peak strength with increasing cycles. The contraction behavior occurred during all the tests, which decreases significantly with increasing loading cycles.

(2) The value of peak stress increases with increasing cycle numbers and reaches a stable value at about the $10^{\text {th }}$ cycles. Both the $\Delta a$ and cycle numbers enhance the contraction of interface.

(3) The increasing of normal stress causes an increase of ultimate peak shear for MDS, CDS, and PCDS stages. The interface displays larger contraction subjected to larger normal stresses during cyclic loading.

(4) The preloading strengthens the peak shear strength, whereas it reduced the contraction deformation of interface.

\section{Data Availability}

The data used to support the findings of this study are available from the corresponding author upon request.

\section{Conflicts of Interest}

The authors declare that they have no conflicts of interest.

\section{Acknowledgments}

This research was substantially supported by Plan for Youth Core Teachers of Henan University of Technology (2015004), Plan for the Key Projects of High Schools of Henan Province (19A560009 and 20A560021), and Provincial Key Laboratory for Grain and Oil Storage Facility and Safety, Henan University of Technology (2016KF-B03).

\section{References}

[1] J. M. Rotter, "Silos and tanks in research and practice: state of the art and current challenges," in Proceedings of the International Association for Shell and Spatial, Structures (IASS) Symposium, Evolution and Trends in Design, Analysis and Construction of Shell and Spatial Structures, pp. 65-76, Valencia, Spain, September-October 2009.

[2] P. Teeuwen, W. Claassen, and M. Baan, "Design and construction of fly ash silo with inverted cone," Structural Engineering International, vol. 22, no. 3, pp. 391-394, 2012.

[3] S. A. Thompson and I. J. Ross, "Compressibility and frictional coefficients of wheat," Transactions of ASAE, vol. 26, no. 4, pp. 1171-1176, 1983.

[4] M. Moya, M. Guaita, P. Aguado, and F. Ayuga, "Mechanical properties of granular agricultural materials, part 2," Transactions of the ASAE, vol. 49, no. 2, pp. 479-489, 2006.

[5] X. Wang, Z. Yang, X. Shu, and J. Feng, "The static contact statuses between granular materials and flat-bottomed steel silos," Powder Technology, vol. 235, pp. 1053-1059, 2013.

[6] ACI 313-97, Standard Practice for Design and Construction of Concrete Silos and Stacking Tubes for Storing Granular Materials, ACI International, Farmington Hills, MI, USA, 1997.

[7] European Committee for Standardization, Eurocode 8 Design of Structures for Earthquake Resistance, Part 4: Silos, Tanks and Pipelines, European Committee for Standardization, Brussels, Belgium, 2006.

[8] R. Ortiz, K. D. Sayre, B. Govaerts et al., "Climate change: can wheat beat the heat?," Agriculture, Ecosystems \& Environment, vol. 126, no. 1-2, pp. 46-58, 2008.

[9] X. Li, Z. Cao, Z. Wei, Q. Feng, and J. Wang, "Equilibrium moisture content and sorption isosteric heats of five wheat varieties in China," Journal of Stored Products Research, vol. 47, no. 1, pp. 39-47, 2011.

[10] F. Ayuga, M. Guaita, P. J. Aguado, and A. Couto, "Discharge and the eccentricity of the hopper influence on the silo wall pressures," Journal of Engineering Mechanics, vol. 127, no. 10, pp. 1067-1074, 2001.

[11] F. Ayuga, M. Guaita, and P. Aguado, "SE-structures and environment," Journal of Agricultural Engineering Research, vol. 78, no. 3, pp. 299-308, 2001.

[12] M. Moya, F. Ayuga, M. Guaita, and P. Aguado, "Mechanical properties of granular agricultural materials," Transactions of the ASAE, vol. 45, no. 5, pp. 1569-1577, 2002. 
[13] M. Moya, P. J. Aguado, and F. Ayuga, "Mechanical properties of some granular agricultural materials used in silo design," International Agrophysics, vol. 27, no. 2, pp. 181-193, 2013.

[14] M. Molenda and M. Stasiak, "Determination of the elastic constants of cereal grains in a uniaxial compression test," International Agrophysics, vol. 16, no. 1, pp. 61-66, 2002.

[15] A. Ramírez, M. Moya, and F. Ayuga, "Determination of the mechanical properties of powdered agricultural products and sugar," Particle \& Particle Systems Characterization, vol. 26, no. 4, pp. 220-230, 2009.

[16] A. Ramírez, J. Nielsen, and F. Ayuga, "Pressure measurements in steel silos with eccentric hoppers," Powder Technology, vol. 201, no. 1, pp. 7-20, 2010.

[17] Q. Zhang and M. G. Britton, "A micromechanics model for predicting dynamic loads during discharge in bulk solids storage structures," Canadian Biosystems Engineering, vol. 45, pp. 5.21-5.27, 2003.

[18] K. Guo, C. Zhou, L. Meng, and X. Zhang, "Seismic vulnerability assessment of reinforced concrete silo considering granular material-structure interaction," The Structural Design of Tall and Special Buildings, vol. 25, no. 18, pp. 10111030, 2016.

[19] Y. Wang, Y. Gao, C. Zeng, and A. H. Mahfouz, "Undrained cyclic behavior of soft marine clay involved combined principal stress rotation," Applied Ocean Research, vol. 81, pp. 141-149, 2018.

[20] Y. Wang, Y. Gao, B. Li, L. Guo, Y. Cai, and A. H. Mahfouz, "Influence of initial state and intermediate principal stress on undrained behavior of soft clay during pure principal stress rotation," Acta Geotechnica, vol. 14, no. 5, pp. 1379-1401, 2019.

[21] F. Ayuga, P. Aguado, E. Gallego, and Á. Ramírez, "New steps towards the knowledge of silos behavior," International Agrophysics, vol. 19, no. 1, pp. 7-17, 2005.

[22] R. Livaoglu and A. Durmuş, "A simplified approximation for seismic analysis of silo-bulk material system," Bulletin of Earthquake Engineering, vol. 14, no. 3, pp. 863-887, 2016.

[23] A. F. Cabalar, K. Dulundu, and K. Tuncay, "Strength of various sands in triaxial and cyclic direct shear tests," Engineering Geology, vol. 156, pp. 92-102, 2013.

[24] C. S. Vieira, M. L. Lopes, and L. M. Caldeira, "Sand-geotextile interface characterisation through monotonic and cyclic direct shear tests," Geosynthetics International, vol. 20, no. 1, pp. 26-38, 2013.

[25] A. Fathi, Z. Moradian, P. Rivard, and G. Ballivy, "Shear mechanism of rock joints under pre-peak cyclic loading condition," International Journal of Rock Mechanics and Mining Sciences, vol. 83, pp. 197-210, 2016.

[26] F.-Y. Liu, P. Wang, X. Geng, J. Wang, and X. Lin, "Cyclic and post-cyclic behaviour from sand-geogrid interface large-scale direct shear tests," Geosynthetics International, vol. 23, no. 2, pp. 129-139, 2016.

[27] Lin, GB 5497-85 Inspection of Grain and Oilseeds Methods for Determination of Moisture, National Bureau of Standards of China, 1985, in Chinese.

[28] Trade Standard of P.R. China SL237, Specification of Soil Test, The Ministry of Water Resources of P.R. China, Beijing, China, 1999, in Chinese.

[29] Y. Xiao, H. Liu, Y. Chen, and J. Jiang, "Strength and deformation of rockfill material based on large-scale triaxial compression tests. I: influences of density and pressure," Journal of Geotechnical and Geoenvironmental Engineering, vol. 140, no. 12, Article ID 04014070, 2014.

[30] C. Ovalle, C. Dano, P.-Y. Hicher, and M. Cisternas, "Experimental framework for evaluating the mechanical behavior of dry and wet crushable granular materials based on the particle breakage ratio," Canadian Geotechnical Journal, vol. 52, no. 5, pp. 587-598, 2015.

[31] Y. Xiao, H. Liu, Y. Sun, H. Liu, and Y. Chen, "Stress-dilatancy behaviors of coarse granular soils in three-dimensional stress space," Engineering Geology, vol. 195, pp. 104-110, 2015.

[32] Y. Xiao, H. Liu, X. Ding, Y. Chen, J. Jiang, and W. Zhang, "Influence of particle breakage on critical state line of rockfill," International Journal of Geomechanics, vol. 16, no. 1, Article ID 04015031, 2016.

[33] C. Zeng and Y. Wang, "Compressive behaviour of wheat from confined uniaxial compression tests," International Agrophysics, vol. 33, no. 3, pp. 347-354, 2019.

[34] C. Zeng and Y. Wang, "The shear strength and dilatancy behavior of wheat stored in silos," Complexity, vol. 2019, Article ID 1547616, 9 pages, 2019. 


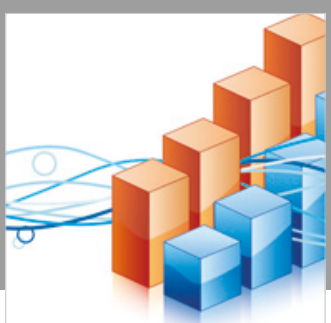

Advances in

Operations Research

\section{-n-m}
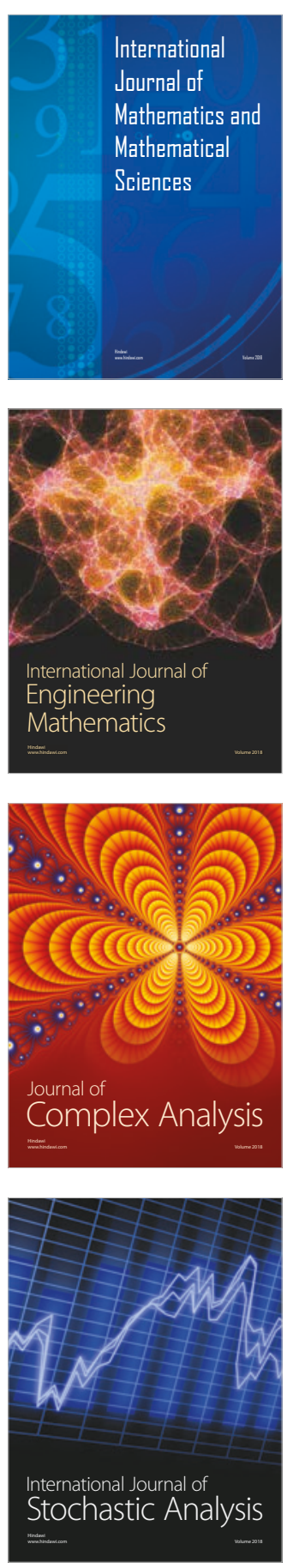
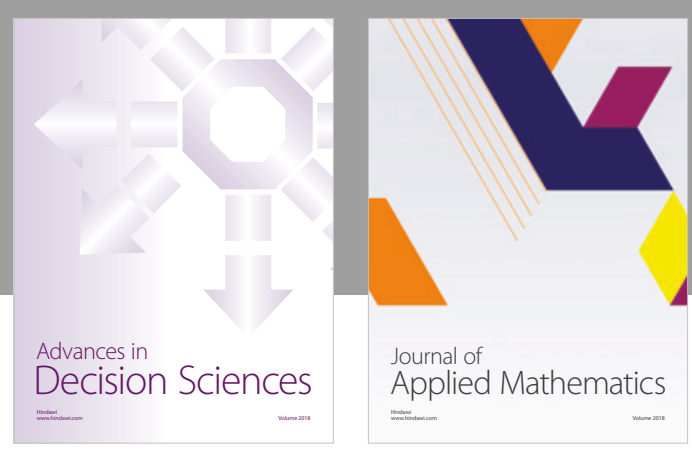

Journal of

Applied Mathematics
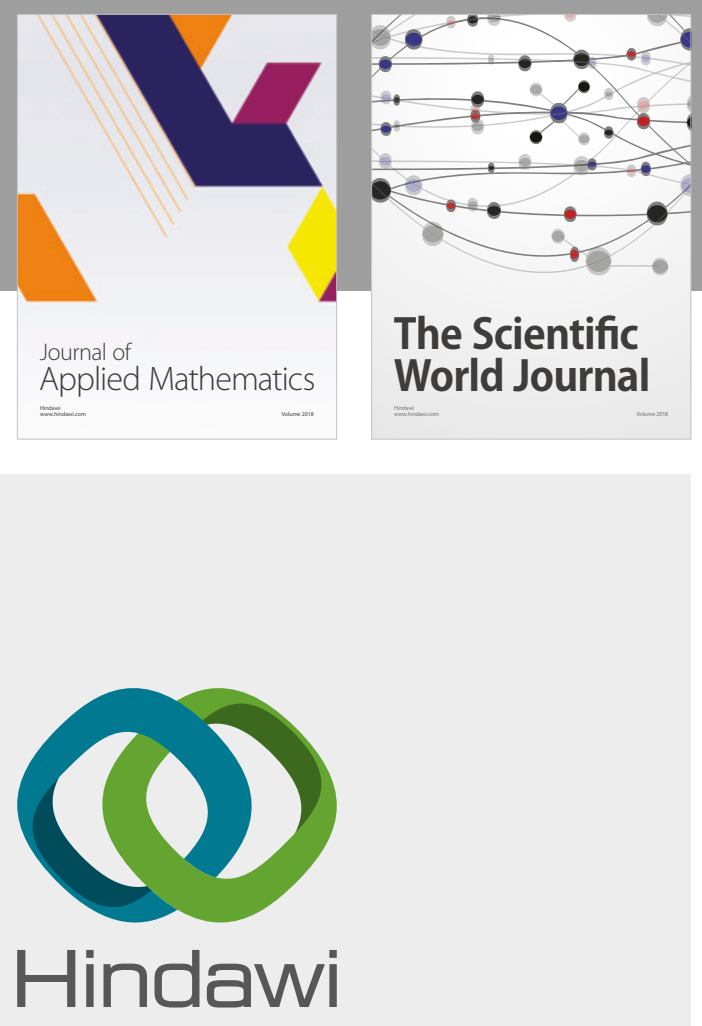

Submit your manuscripts at

www.hindawi.com

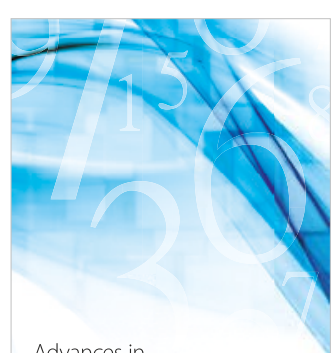

Advances in
Numerical Analysis
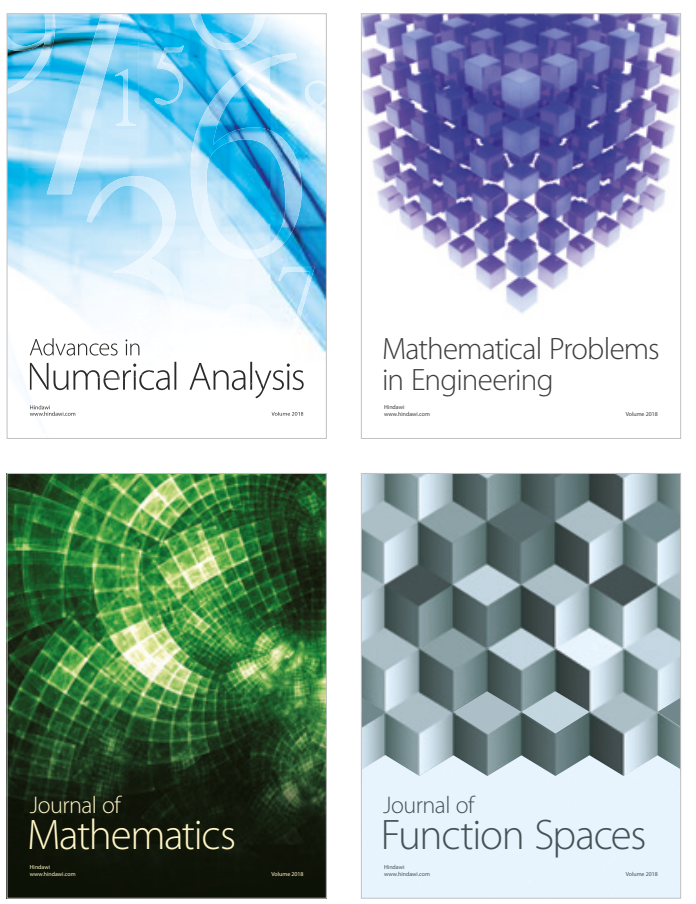

Mathematical Problems in Engineering

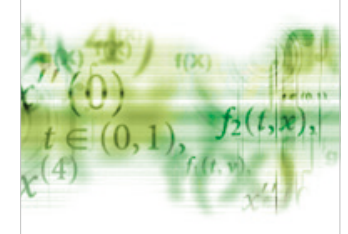

International Journal of

Differential Equations

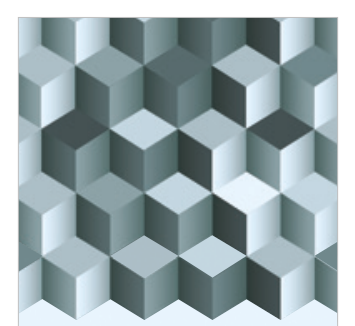

Journal of

Function Spaces
The Scientific

World Journal

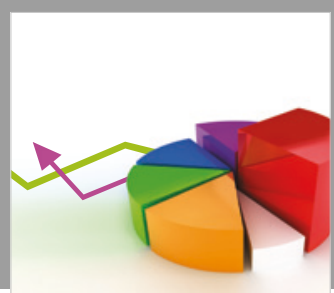

Journal of

Probability and Statistics
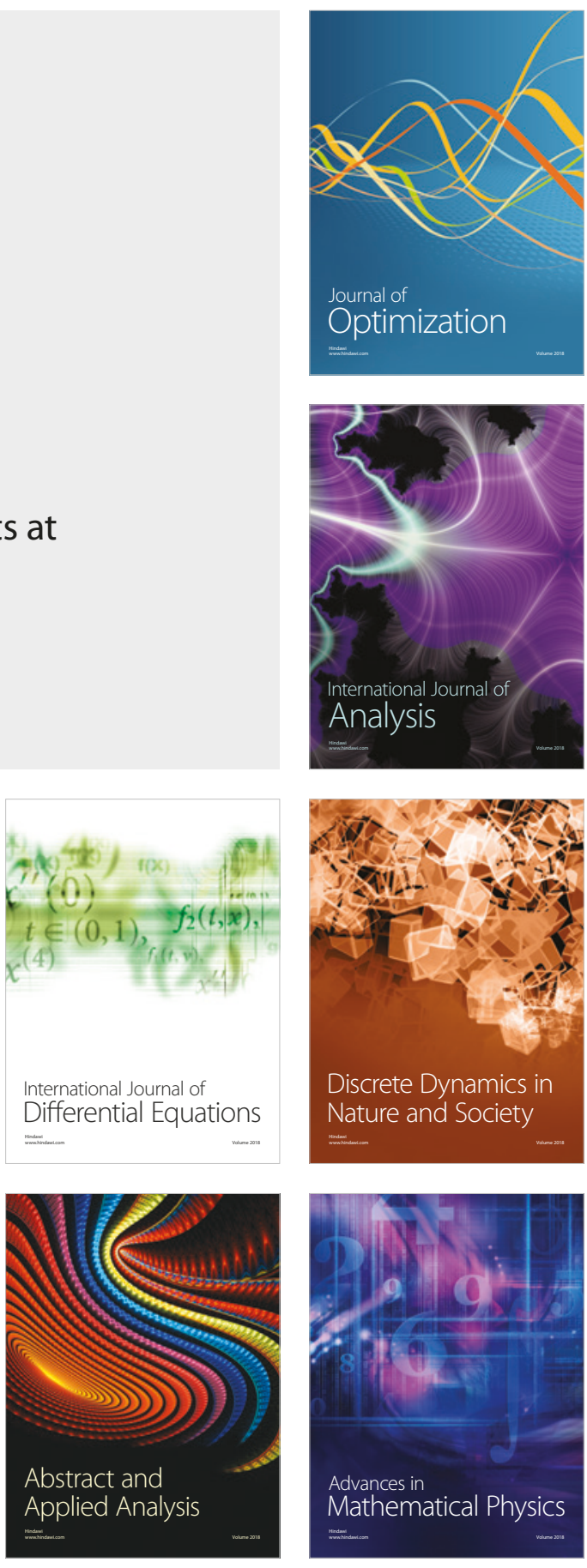